University of Nebraska - Lincoln

DigitalCommons@University of Nebraska - Lincoln

$3-1-2003$

\title{
NATURAL CONVECTION AND SOLID PHASE COMBUSTION
}

S E. Whitney

Department of Chemical Engineering, University of Nebraska-Lincoln

Hendrik J. Viljoen

University of Nebraska-Lincoln, hviljoen1@unl.edu

Follow this and additional works at: https://digitalcommons.unl.edu/chemengreaction

Part of the Chemical Engineering Commons

Whitney, S E. and Viljoen, Hendrik J., "NATURAL CONVECTION AND SOLID PHASE COMBUSTION" (2003). Papers in Reaction Kinetics. 6.

https://digitalcommons.unl.edu/chemengreaction/6

This Article is brought to you for free and open access by the Chemical and Biomolecular Engineering Research and Publications at DigitalCommons@University of Nebraska - Lincoln. It has been accepted for inclusion in Papers in Reaction Kinetics by an authorized administrator of DigitalCommons@University of Nebraska - Lincoln. 


\section{NATURAL CONVECTION AND SOLIDPHASE COMBUSTION}

\section{S. E. WHITNEY, H. J. VILJOEN.}

Chemical Engineering Communications, 190: 393 - 430, 2003 Copyright (C) 2003 Taylor \& Francis

Self-propagating high-temperature synthesis [SHS] is a combustion process involving two or more solid reactants. The typical SHS configuration consists of a cylindrical preform of mixed powders, placed in an inert gas chamber, and ignited at one end. In past studies, interaction between the solid phase and the ambient gas phase has been limited to heat losses from the solid; the influence of natural convection on the solid phase has never been considered. In this study, computational fluid dynamics [CFD] is used, and it is shown that intense convection flow develops in the proximity of the combustion front. Gas flows adjacent to reacted solid material, heats up, and when it reaches the unreacted solid heat is transferred from the gas to the solid phase, which aids solid phase thermal conduction in preheating the material. The effect is stronger than expected, and it could stabilize the combustion of structured reactants like roll-ups of foils and wires. Combustion parallel and antiparallel to gravity is investigated for different burning velocities. At low propagation veloci-

ties, the natural convection cell forms a torus that is seated above the combustion front. At high propagation velocities, the convection flow cannot track the combustion front, and Tollmien-Schlichting waves form. Constant front propagation and planar oscillations of the combustion front lead to increasingly complex flows. Finally, the heat exchange between the gas and solid for constant front propagation is compared to analytical solutions.

\section{Keywords:}

Natural convection; Solid phase combustion; Enhanced preheating 


\section{NATURAL CONVECTION AND SOLIDPHASE COMBUSTION}

\section{S. E. WHITNEY, H. J. VILJOEN.}

Chemical Engineering Communications, 190: 393 - 430, 2003 Copyright (C) 2003 Taylor \& Francis

Solid cylinders for self-propagating high-temperature synthesis [SHS] applications are prepared in different ways: preforms of mixed powders, foil roll-ups, and wire twists. These cylinders contain two or more reactants that undergo an exothermic synthesis reaction. Examples include the synthesis of intermetallics, e.g., TipNi, and carbides like TipC. One end of the cylinder is ignited and the reaction front progresses in the axial direction toward the other end. The rate of this propagation depends on the heat transfer to the unburned section-which in turn depends on solid properties [density, thermal conductivity, and heat capacity] and on heat exchange with the surroundings. Previous research has often ignored the latter effect. If the thermal conductivity is large or if the cylinder radius is large, then the heat transferred to the surroundings is negligible compared to the heat conducted to the unreacted solids. Papers that have considered heat exchange with the surroundings have focused only on heat losses : radiation from the cylinder and conduction losses to the

surroundings. The focus of the gravity-related studies was on intrasample effects [gas-solid reactions, where natural convection affects gas flow in the sample], but the conjugate flow problem [where natural convection outside the sample affects the combustion] has been largely overlooked. The interaction between natural convection and chemical reaction has been extensively studied for porous and homogeneous media [Viljoen and Hlavacek, 1988; Gatica et al., 1989; Viljoen et al., 1989, 1990], investigating the influence of natural convection on ignition and induction periods. Matkowsky and coworkers [1997a,b] did a comprehensive study of natural convection in the realm of filtration combustion. The role of surrounding fluid on heat losses from gasless combustion synthesis systems has been included in previous analysis [Thiart et al., 1992], but feedback of thermal energy to the combustion system has not been considered. The feedback of thermal energy from the gas phase to the solid phase becomes particularly important when the solid system is near an extinction limit. This is more likely for slender cylinders, found in the synthesis of intermetallic structures. Vadchenko [1987] was one of the first researchers who investigated the combustion of bimetallic samples. One wire was coated with another metal, but the disadvantage of this method was the dramatic change in the geometry caused by melting and the 


\section{NATURAL CONVECTION AND SOLIDPHASE COMBUSTION}

\section{S. E. WHITNEY, H. J. VILJOEN.}

Chemical Engineering Communications, 190: 393 - 430, 2003 Copyright (C) 2003 Taylor \& Francis

formation of separate drops. Anselmi-Tamburini and Munir [1989] studied a multilayered sample consisting of $\mathrm{Ni}$ and $\mathrm{Al}$ foils. The prominence and influence of natural convection on the combustion process is strongly dependent on the propagation velocity of the combustion front. In the conjugate problem, they are interdependent. Typical propagation velocities are $10 \_12 \mathrm{~cm} / \mathrm{s}$. Ma et al. [1990] studied direct combustion of multilayered samples [Ni and Al layers 10_20 nm thick], and velocities of $400 \mathrm{~cm} / \mathrm{s}$ were measured. Dyer et al. [1994], Dyer and Munir [1995], and Weihs [1997] easured velocities of 60_200 cm/s for multilayered samples prepared by electron beam evaporation and sputtering. Change in the stoichiometry of the layered samples of Ni:Al from 1:1 to 3:1 decreased the velocities. To minimize unwanted side reactions, the cylinders are placed in an inert atmosphere such as argon or helium gas. When thermal conductivity of the solids is low or if the cylinder radius is small, a large portion of the heat generated from the exothermic reaction is transferred to the gas instead of conducting to the unburned section. This heat does not disappear. Natural convection will transport the heat, either to the unreacted solids or away from the preform, depending on the combustion front velocity and orientation with respect to gravity. Under normal conditions, the amount of heat transferred to the unreacted zone through natural convection may be a significant fraction of the heat transferred by conduction. This energy will preheat the solids, hence increasing the combustion front velocity.

\section{SYSTEM DESCRIPTION}

\section{Mathematical Model of Solid Phase}

The system under consideration consists of a solid cylinder, placed vertically on an adiabatic surface and surrounded by inert gases. Since many different solid materials may be reacted and many different size cylinders may be formed, a generic system is selected for analysis. The chosen cylinders are $L=10 \mathrm{~cm}$ long and have a radius of $r 0=1 \mathrm{~cm}$. In a section below, analytical solutions are developed; these analytical solutions are used to ex- 


\section{NATURAL CONVECTION AND SOLIDPHASE COMBUSTION}

\section{S. E. WHITNEY, H. J. VILJOEN.}

Chemical Engineering Communications, 190: 393 - 430, 2003 Copyright (C) 2003 Taylor \& Francis

plore the effect of alternative system dimensions. The combustion front in SHS systems can propagate in a variety of different modes. The constant velocity propagating combustion front becomes unstable for certain conditions, and the combustion front propagates in an oscillatory manner. Several oscillatory modes are observed. In this analysis two modes have been considered:

1] axisymmetric combustion with a steady combustion front velocity, $\mathrm{Vf}$, and 2] axisymmetric combustion with a planar oscillating combustion front velocity.

The conjugate problem combines combustion-induced gas flow and the effect of gas flow on combustion, solved in a self-consistent manner. We want to focus on the induced gas flow, and although the heat transfer from the gas to the solid phase is also calculated, we did not model the kinetics. Instead, the temperature profile of the solid is defined a priori as a traveling wave function. Both the propagation modes are described this way. The temperature is described by the following equation:

$T_{w a l l}= \begin{cases}T_{w} & \text { if } \bar{x} \leq V_{f} t+\frac{V_{a}}{f}[1-\cos (f t)] \\ T_{0}+\left(T_{w}-T_{0}\right) e^{-500\left(\bar{x}-V_{f} t-\frac{V_{a}}{f}[1-\cos (f t)]\right)} & \text { if } \bar{x}>V_{f} t+\frac{V_{a}}{f}[1-\cos (f t)]\end{cases}$

When $V_{a}=0$ in Equation [1], constant propagation is modeled [mode 1], otherwise it describes the planar oscillating mode [mode 2]. This computational fluid dynamics [CFD] research covers the full range of velocities and oscillating frequencies but is limited to the case where $T_{w}=2000 \mathrm{~K}$ and $\mathrm{T}_{0}=300 \mathrm{~K}$. The values chosen were for a typical SHS reaction starting at room temperature and an adiabatic combustion

temperature of $2000 \mathrm{~K}$. The exponent for temperature decay $-500 \mathrm{~m}$ in Equation [1] - is also a typical value where the majority of preheating occurs in $1 \mathrm{~cm}$. Specific values of the 


\section{NATURAL CONVECTION AND SOLIDPHASE COMBUSTION}

\section{S. E. WHITNEY, H. J. VILJOEN.}

Chemical Engineering Communications, 190: 393 - 430, 2003 Copyright (C) 2003 Taylor \& Francis

adiabatic combustion temperature and preheating exponent can be calculated with a onedimensional kinetic model of the solid reaction. The analytical solutions below can predict the effect of using different constants. In figure 1, the temperature profile is shown when the combustion front has reached $5 \mathrm{~cm}$. :

\section{Mathematical Model of Gas Phase:}

The system under consideration consists of a solid cylinder surrounded by inert gases. For our simulations, argon gas has been used. All gas properties except density are assumed constant at their standard values. For argon these are:

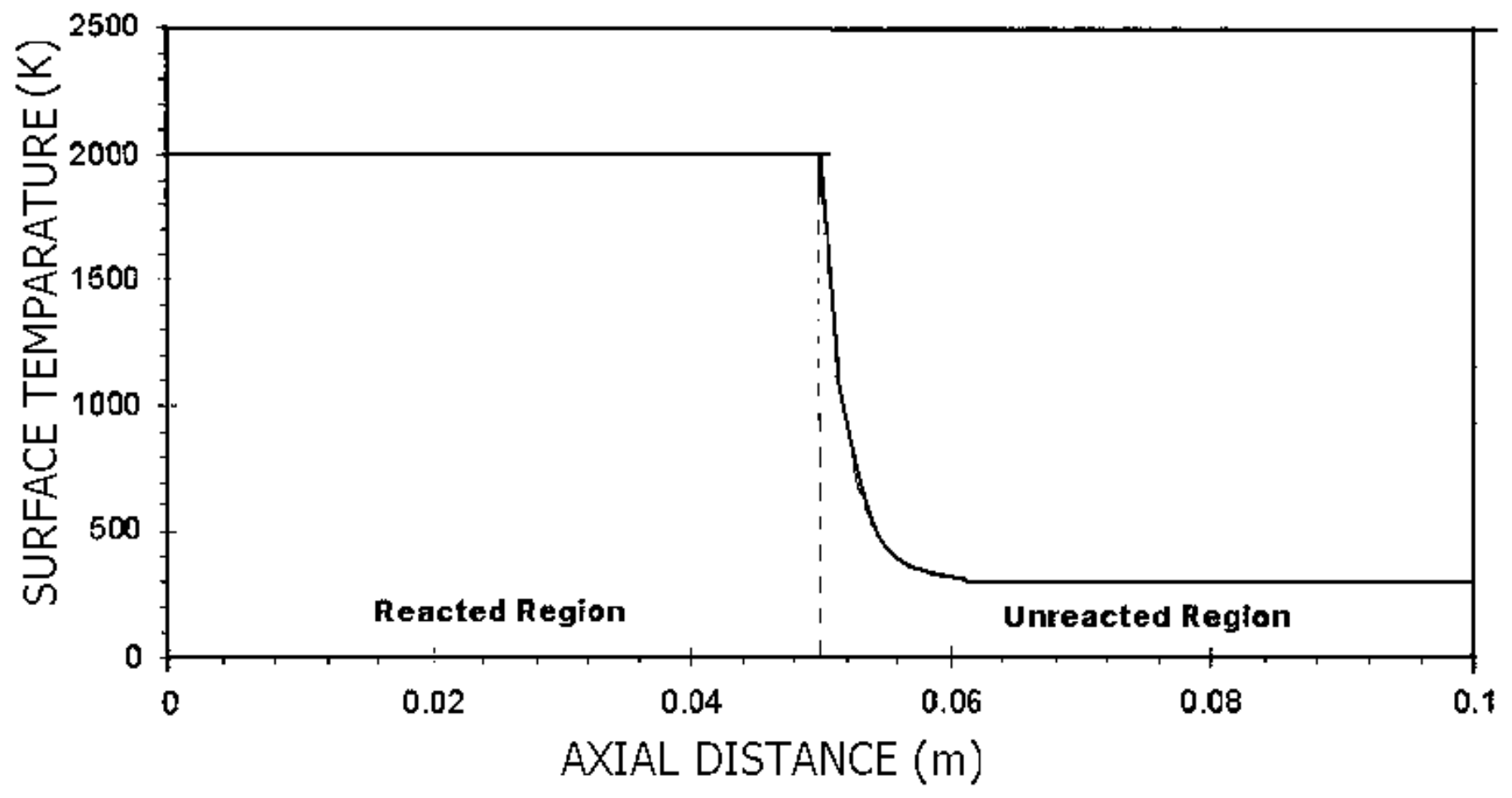

Fig.1 Temparature Profile Used in all Simulations 
NATURAL CONVECTION AND SOLIDPHASE COMBUSTION

S. E. WHITNEY, H. J. VILJOEN.

Chemical Engineering Communications, 190: 393 - 430, 2003 Copyright @ 2003 Taylor \& Francis

$$
C_{p}=520.6 \frac{\mathrm{J}}{\mathrm{kg} \cdot \mathrm{K}} ; k=0.0158 \frac{\mathrm{W}}{\mathrm{m} \cdot \mathrm{K}} ; \mu=2.125 \cdot 10^{-5} \frac{\mathrm{kg}}{\mathrm{m} \cdot \mathrm{s}}
$$

Density is modeled as an ideal gas at $\mathrm{P}_{0}=1 \mathrm{~atm}$ base pressure. Given the temperature boundary condition in Figure 1, the time dependent state of the gas has been modeled. The commercial CFD program, Fluent 5.4, is used. Fluent solved the governing equations for the inert gas surrounding the cylinder. For 2D axisymmetric flow the governing equations are:

Continuity [mass conservation]:

$$
\frac{\partial \rho}{\partial t}+\frac{\partial(\rho u)}{\partial x}+\frac{\partial(\rho v)}{\partial r}+\frac{\rho v}{r}=0
$$

Momentum conservation [axial $\mathrm{x}$ direction]:

$$
\begin{aligned}
& \frac{\partial(\rho u)}{\partial t}+\frac{1}{r} \frac{\partial(r \rho u u)}{\partial x}+\frac{1}{r} \frac{\partial(r \rho v u)}{\partial r} \\
& =\left\{\begin{array}{l}
-\frac{\partial P}{\partial x}+\frac{1}{r} \frac{\partial}{\partial x}\left[r \mu\left(2 \frac{\partial u}{\partial x}-\frac{2}{3}\left[\frac{\partial u}{\partial x}+\frac{\partial v}{\partial r}+\frac{v}{r}\right]\right)\right] \\
+\frac{1}{r} \frac{\partial}{\partial r}\left[r \mu\left(\frac{\partial u}{\partial r}+\frac{\partial v}{\partial x}\right)\right]-\rho g
\end{array}\right\}
\end{aligned}
$$


NATURAL CONVECTION AND SOLIDPHASE COMBUSTION

S. E. WHITNEY, H. J. VILJOEN.

Chemical Engineering Communications, 190: 393 - 430, 2003 Copyright (C) 2003 Taylor \& Francis

Momentum conservation [radial $r$ direction]:

$$
\begin{aligned}
\frac{\partial(\rho v)}{\partial t}+ & \frac{1}{r} \frac{\partial(r \rho u v)}{\partial x}+\frac{1}{r} \frac{\partial(r \rho v v)}{\partial r} \\
= & \left\{\begin{array}{l}
-\frac{\partial P}{\partial r}+\frac{1}{r} \frac{\partial}{\partial x}\left[r \mu\left(\frac{\partial v}{\partial x}+\frac{\partial u}{\partial r}\right)\right] \\
+\frac{1}{r} \frac{\partial}{\partial r}\left[r \mu\left(2 \frac{\partial v}{\partial r}-\frac{2}{3}\left[\frac{\partial u}{\partial x}+\frac{\partial v}{\partial r}+\frac{\nu}{r}\right]\right)\right] \\
-\frac{2 \mu v}{r^{2}}+\frac{2 \mu}{3 r}\left[\frac{\partial u}{\partial x}+\frac{\partial v}{\partial r}+\frac{v}{r}\right]
\end{array}\right.
\end{aligned}
$$




\section{NATURAL CONVECTION AND SOLIDPHASE COMBUSTION}

\section{S. E. WHITNEY, H. J. VILJOEN.}

Chemical Engineering Communications, 190: 393 - 430, 2003 Copyright (C) 2003 Taylor \& Francis

Energy conservation:

$$
\frac{\partial(\rho E)}{\partial t}+\frac{\partial[u(\rho E+P)]}{\partial x}+\frac{\partial[v(\rho E+P)]}{\partial r}=k\left[\frac{1}{r} \frac{\partial T}{\partial r}+\frac{\partial^{2} T}{\partial r^{2}}+\frac{\partial^{2} T}{\partial x^{2}}\right]
$$

Where

$$
E=C_{p}\left(T-T_{r e f}\right)-\frac{P}{\rho}+\frac{u^{2}+v^{2}}{2}
$$

The system is closed by an equation of state, and the ideal gas law has been used:

$P=\rho R T$

Fluent solves these governing equations numerically using the finite volume method to find the gas flow, gas temperature, and heat flux between the cylinder and the gas.

\section{COMPUTATIONAL FLUID DYNAMICS MODELING}

The finite volume method requires a mesh of the solution domain. At the center of each cell in the mesh, the governing equations are iterated for a specified time step, Dt. The gas do- 


\section{NATURAL CONVECTION AND SOLIDPHASE COMBUSTION}

\section{S. E. WHITNEY, H. J. VILJOEN.}

Chemical Engineering Communications, 190: 393 - 430, 2003 Copyright (C) 2003 Taylor \& Francis

main is large compared to the size of the cylinder; the gas essentially reaches out toward infinity, but the governing equations must be solved on a finite domain. Thus the gas is modeled over a domain $\mathrm{r}=10 \mathrm{~cm}$ in the radial direction and $\mathrm{x}=15 \mathrm{~cm}$ in the axial direction [see Figure 2]. Outside that domain, pressure is assumed to be equal to Po [ambient gas pressure], and flow entering the domain from beyond that boundary has a temperature of To [ambient gas temperature]. Determination of Cell Size The accuracy of CFD calculations is poor when mesh cells are of poor quality-cells that are too large, have distorted shapes, step gradients in the cell size, etc. As the number of cells increase, these numerical errors asymptotically decrease but the computational expense increases. $A$ trial simulation was completed with square cell sizes varying from $5 \mathrm{cells} / \mathrm{cm}$ to $20 \mathrm{cells} / \mathrm{cm}$ in both the axial and radial directions; the results when the reaction front is located at $x=1: 5 \mathrm{~cm}$ are in Figure $3 a$. 
NATURAL CONVECTION AND SOLIDPHASE COMBUSTION

S. E. WHITNEY, H. J. VILJOEN.

Chemical Engineering Communications, 190: 393 - 430, 2003 Copyright (C) 2003 Taylor \& Francis

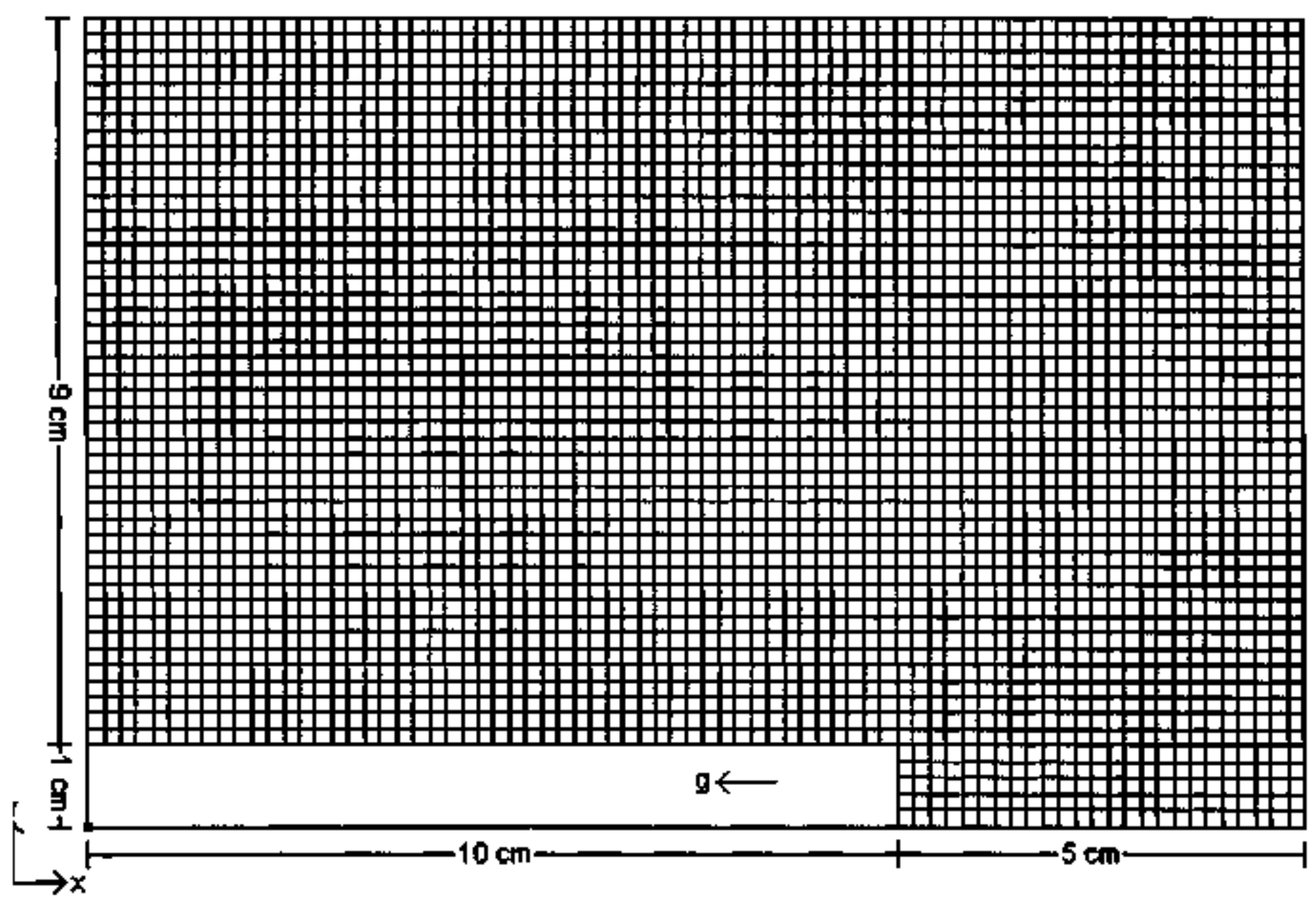

Fig. 2 Axisymmetric mesh with 5 cells/ $\mathrm{cm}$. The bottom line the center axis 


\section{NATURAL CONVECTION AND SOLIDPHASE COMBUSTION}

\section{S. E. WHITNEY, H. J. VILJOEN.}

Chemical Engineering Communications, 190: 393 - 430, 2003 Copyright (C 2003 Taylor \& Francis
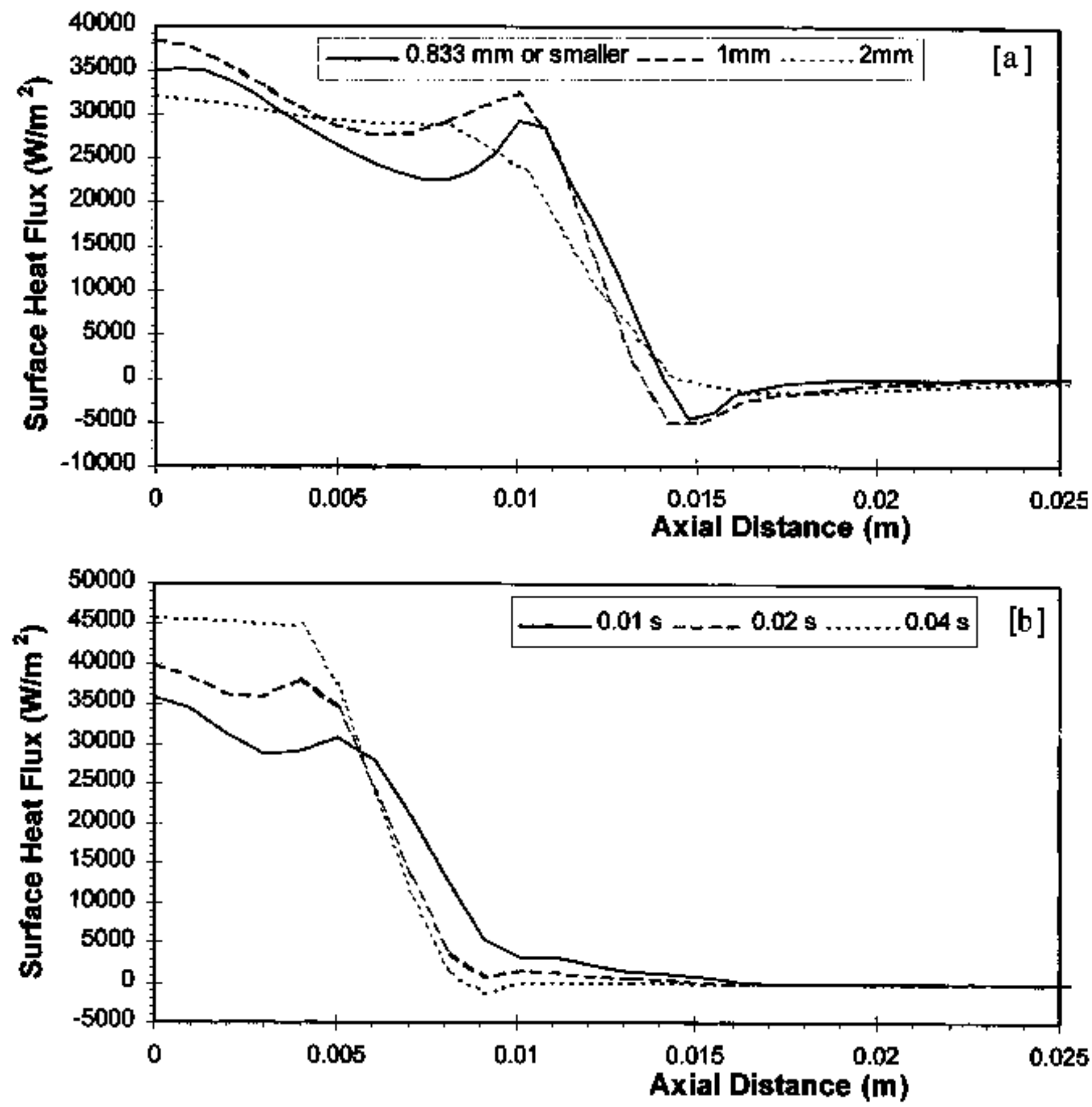

Fig.3. Heat transfer to gas from cylinder [a] with different cell size:0.833 or smaller, $1 \mathrm{~mm}$ and $2 \mathrm{~mm}$ squares, [b] with different steps $0.01 \mathrm{~s}$ and $0.04 \mathrm{~s}$ 


\section{NATURAL CONVECTION AND SOLIDPHASE COMBUSTION}

\section{S. E. WHITNEY, H. J. VILJOEN.}

Chemical Engineering Communications, 190: 393 - 430, 2003 Copyright (C) 2003 Taylor \& Francis

Two parts of the heat transfer curves were considered important: the section over the hot burned solids, axial position $<1.5 \mathrm{~cm}$, and the section where the gas

preheats the unreacted solids, axial position $>1.5 \mathrm{~cm}$. As can be discerned

from Figure 3[a], the profile is flat when the coarse mesh is used. More details appear as the mesh is refined. However, the computational time required ranged from hours with the large cells to days with the small cells. From these tests it was determined that using $12 \mathrm{cells} / \mathrm{cm}$ [0.833 $\mathrm{mm}$ edges] gave the fastest results without significantly sacrificing accuracy. Within the $10 \mathrm{~cm}$ by $15 \mathrm{~cm}$ gas domain, the inert gas is meshed into 20,160 square cells. For each time step there are 80,640 quations and unknowns to solve [20,160 cells _ 4 governing equations/cell].

Determination of Time Step Size:

Each of the CFD calculations is time dependent, so the governing equations are discretized in both space and time. The size of the time step, like the cell size, affects the accuracy and computer expense of the simulations. Figure $3[b]$ shows the effect of the time step on the heat transfer profile for a combustion front velocity of $10 \mathrm{~cm} / \mathrm{s}$. The largest time step, Dt $=0.04 \mathrm{~s}$, took several hours of computer calculations to complete a simulation, and the smallest time step, $0.01 \mathrm{~s}$, took several days. At the moment shown in Figure $3[\mathrm{~b}]$, the gas is colder than the adjacent cylinder for the entire cylinder length. Thus the negative heat transfer shown for the largest time steps is a numerical inaccuracy that cannot be tolerated. The ideal time step size was $0.01 \mathrm{~s}$. For different simulations, the ideal time step size varies. As the combustion velocity, $\mathrm{Vf}_{\mathrm{f}}$, increases the required time step size decreases, roughly following the relation $\mathrm{Dt} \_1 \mathrm{~mm}=\mathrm{Vf}_{\mathrm{f}}$.

\section{CFD RESULTS:}




\section{NATURAL CONVECTION AND SOLIDPHASE COMBUSTION}

\section{S. E. WHITNEY, H. J. VILJOEN.}

Chemical Engineering Communications, 190: 393 - 430, 2003 Copyright (C) 2003 Taylor \& Francis

In this section the results of the gas flow and heat transfer for the two modes of propagation are presented. Of particular interest is the heat exchange between the phases, presented in the form of a Nusselt number, $\mathrm{Nu}=$

$$
N u=\frac{h r_{0}}{k}=\frac{q_{g} r_{0}}{k\left(T_{w a l l}-T_{r e f}\right)}
$$

The results will show that some of the cases have a gas preheating effect that is significant; with others it is negligible. In all cases, the local heat flux by convection, $\mathrm{qg}$, is small compared to the heat flux by conduction, qs. The axial thermal flux in the solid phase is a maximum at $\mathrm{x}=0 \mathrm{p}$ and it is estimated as:

$$
q_{s}=-k_{s} \frac{d T}{d x}=\rho_{s} C p_{s} V_{f}\left(T_{w}-T_{0}\right)
$$

However, the power transferred by natural convection, $\mathrm{Pg}$, to the unreacted zone is significant because the lateral heat transfer area is much larger than the cross-sectional area of the cylinder. The total power transferred to the unreacted solids is the heat flux times area:

where $q g$ is the average heat flux by natural convection and $L$ is the remaining length of cyl-

$$
P_{s}=q_{s} A_{c}=\pi q_{s} r_{0}^{2} \text {, and } P_{g}=-2 \pi \overline{q_{g}} L
$$

inder ahead of the combustion front. The ratio of preheating by natural convection to solid conduction is $\mathrm{Pg}$

$$
\frac{P_{g}}{P_{s}}=-\frac{2 L}{r_{0}} \frac{\overline{q_{g}}}{q_{s}}=-\frac{2 L \overline{q_{g}}}{r_{0} \rho_{s} C p_{s} V_{f}\left(T_{w}-T_{0}\right)}
$$

The following CFD results show three possibilities: 


\section{NATURAL CONVECTION AND SOLIDPHASE COMBUSTION}

\section{S. E. WHITNEY, H. J. VILJOEN.}

Chemical Engineering Communications, 190: 393 - 430, 2003 Copyright (C) 2003 Taylor \& Francis

1. $q_{g}<0$, gas preheating is important. Even when $q_{g} q_{s}$, natural convection is significant when $L \quad$ ro. When combustion of long thin cylinders is modeled, consideration must be given to natural convection effects.

2. $q g<0$, gas preheating is insignificant; this occurs in short, thick cylinders.

3. $q g>0$, no preheating is present.

\section{Constant Combustion Front Velocity}

There is an induction phase associated with the natural convection. Characteristic lines for the rising speed of the natural convection cell [a torus in this case] may differ from the characteristic line of combustion front propagation. If the cell rises faster than the combustion front propagates, an asymptotic flow is approached that we have termed funnel flow. This is a quasi-steady convection flow parallel to the cylinder surface, which could be approximated by steady convection. In Figure 4 , the velocity vector field is shown at three instances, $t=0.5$ $\mathrm{s}, \mathrm{t}=1.0 \mathrm{~s}$, and $\mathrm{t}=2.0 \mathrm{~s}$. This captures the flow history at the induction stage, intermediate stage [combustion front and torus in the same vicinity], and the asymptotic case. In Figure $4[a]$, the combustion front has propagated only a short distance from the adiabatic base and the convection cell is still developing. Note the counterclockwise rotation of the flow. In 


\section{NATURAL CONVECTION AND SOLIDPHASE COMBUSTION}

\section{S. E. WHITNEY, H. J. VILJOEN.}

Chemical Engineering Communications, 190: 393 - 430, 2003 Copyright (C) 2003 Taylor \& Francis
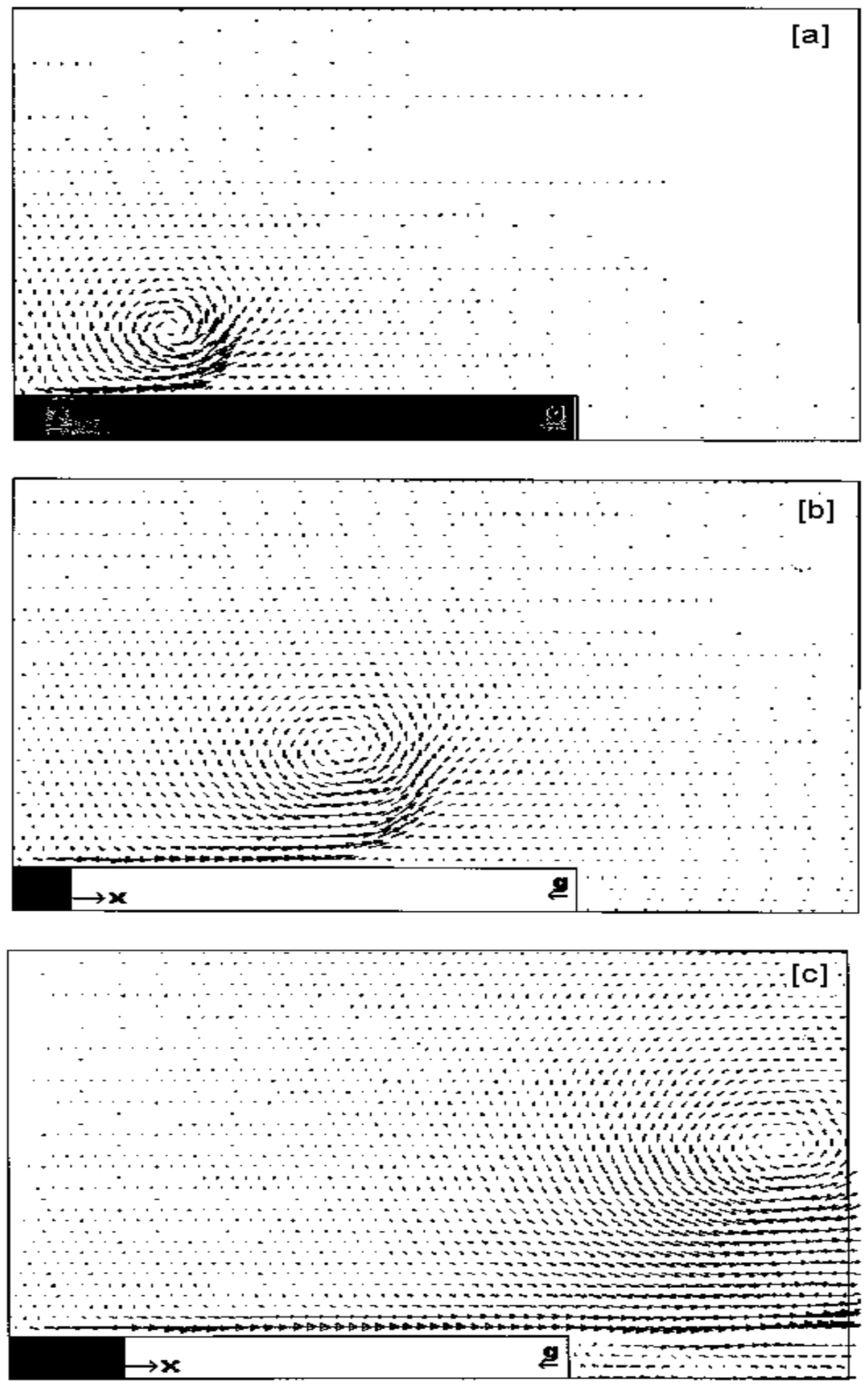

Fig 4. Axisymmetric view of starting vortex formed as the solid ignites on the bottom end at $[\mathrm{a}]=0.5 \mathrm{~s},[\mathrm{~b}] \mathrm{t}=1.0 \mathrm{~s},[\mathrm{c}] \mathrm{t}=2.0 \mathrm{~s}$. 


\section{NATURAL CONVECTION AND SOLIDPHASE COMBUSTION}

\section{S. E. WHITNEY, H. J. VILJOEN.}

Chemical Engineering Communications, 190: 393 - 430, 2003 Copyright (C) 2003 Taylor \& Francis

Figure $4[b]$, the convection cell has moved up much faster than the combustion front and the flow is quasi-parallel to the cylinder behind the torus. Near the torus, the flow bends away from the cylinder. In Figure $4[\mathrm{c}]$, the cell has left the computational domain, and funnel-like flow across the cylinder has developed. The torus does not rise at a constant velocity, but it appears to oscillate. The oscillatory effect is not unexpected, because two different processes determine its displacement. The combustion rate of the solid defines a dynamic temperature boundary condition that drives the natural convection, but internal to the fluid exists the competition between viscous and buoyancy forces [i.e., Rayleigh number] that determines another time scale for the displacement of the torus. The center of the torus has been mapped as a function of position [Figure 5]. The empirical functions reported in Table I describe the position of the torus center. Note that increased velocity of combustion increases the frequency of oscillation [the disparity between the two time scales increases]. Also the amplitude is greatest for moderate combustion front velocities, since the torus is near the combustion front position.

Five trends are observed in the solid/gas heat transfer:

1] combustion in the absence of gravity,

2] combustion parallel to gravity, $\mathrm{Vf}_{\mathrm{f}}<0 \mathrm{~cm} / \mathrm{s}$,

3] slow combustion front velocity, $0 \mathrm{~cm} / \mathrm{s}<V_{f}-8 \mathrm{~cm} / \mathrm{s}$, antiparallel to gravity, 4] moderate combustion front velocity, $8 \mathrm{~cm} / \mathrm{s}<V_{f} \_18 \mathrm{~cm} / \mathrm{s}$, anti parallel to gravity, 5] fast combustion front velocity, $V_{f} 18 \mathrm{~cm} / \mathrm{s}$, antiparallel to gravity. 


\section{NATURAL CONVECTION AND SOLIDPHASE COMBUSTION}

\section{S. E. WHITNEY, H. J. VILJOEN.}

Chemical Engineering Communications, 190: 393 - 430, 2003 Copyright (C) 2003 Taylor \& Francis

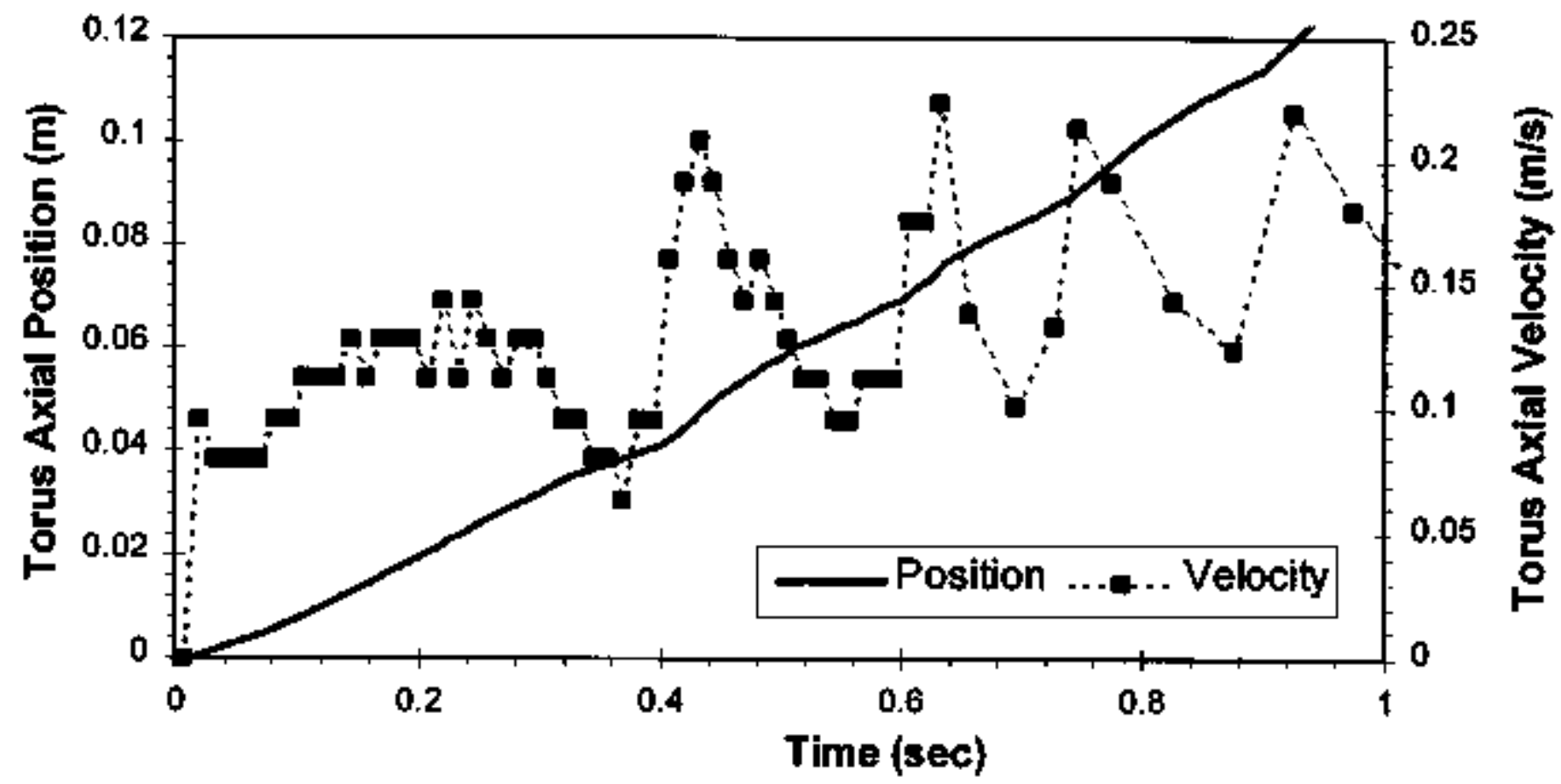

Fig 5. Axial position location of maximum stream function and velocity of the starting vortex for $10 \mathrm{~cm} / \mathrm{s}$ combustion front velocity

\section{Combustion without Gravity:}

In Figure 6[a] the local Nusselt number along the cylinder wall is plotted at three different times for argon gas in the absence of gravity. Combustion front propagation is constant at $\mathrm{V}_{\mathrm{f}}$ $=p 1 \mathrm{~cm} / \mathrm{s}$; the positive sign indicates that the propagation is upwards from the cylinder base [gravity vector when present is negative]. Fluid motion is induced by pressure gradients due to density differences. The flow pattern [stream function contours] is shown in Figure 6[b]. The velocities are very small and the maximum velocities are less than $5 \mathrm{mms}$ _. No motion exists for a Boussinesq approximated solution in this case. The Nusselt number travels as a spike along the cylinder surface. Behind the combustion front location, the heat transfer is conduction dominated due to the small flow of gas. Thus, the Nusselt number behind the combustion front is small positive. A small amount of hot gas lies just ahead of the combustion front [some heated gas has expanded and some heat has conducted through the gas in front of the combustion front]; this temperature profile is shown in Figure 6[c]. Thus, there is 


\section{NATURAL CONVECTION AND SOLIDPHASE COMBUSTION}

\section{S. E. WHITNEY, H. J. VILJOEN.}

Chemical Engineering Communications, 190: 393 - 430, 2003 Copyright (C) 2003 Taylor \& Francis

a thin negative spike in the Nusselt number just past the combustion front location. Further ahead of the combustion front this spike exponentially decays since the gas above the cylinder gets colder. Due to the small area of preheating, natural convection preheating is negligible without gravity. Combustion Parallel to Gravity. Natural convection preheating is suppressed when the reaction propagates downwards at $V_{f}=-1 \mathrm{~cm} / \mathrm{s}$. The results shown in Figures 7[a]_[c] support this. Behind the combustion

\begin{tabular}{lcc}
\hline $\begin{array}{l}\text { Combustion front } \\
\text { velocity, } V_{f}(\mathrm{~m} / \mathrm{s})\end{array}$ & $\begin{array}{c}\text { Axial position of } \\
\text { vortex center }(\mathrm{m})\end{array}$ & $\begin{array}{c}\text { Radial position of } \\
\text { vortex center }(\mathrm{m})\end{array}$ \\
\hline 0.01 & $0.0705\left(1-e^{-16.5 t}\right)$ & $0.0221-0.00461 \cos (9.95 t)$ \\
& $+0.0115 \cos (7.07 t)$ & \\
0.10 & $0.148\left(1-e^{-9.10 t}\right)$ & $0.0438-0.045 \cos (339 t)$ \\
0.25 & $-0.0550 \cos (36.4 t)$ & \\
& $0.250\left(1-e^{-16.1 t}\right)$ & $0.0605+0.00418 \cos (46.5 t)$ \\
1.00 & $-0.00789 \cos (146 t)$ & \\
& $1.81\left(1-e^{-4.58 t}\right)$ & $0.0529+0.0231 \cos (149 t)$ \\
& $-0.0127 \cos (326 t)$ & \\
\hline
\end{tabular}

Table 1 Approximate position of the vortex centre[maximum of the stream function] for steady combustion front velocities 


\section{NATURAL CONVECTION AND SOLIDPHASE COMBUSTION}

\section{S. E. WHITNEY, H. J. VILJOEN.}

Chemical Engineering Communications, 190: 393 - 430, 2003 Copyright (C) 2003 Taylor \& Francis
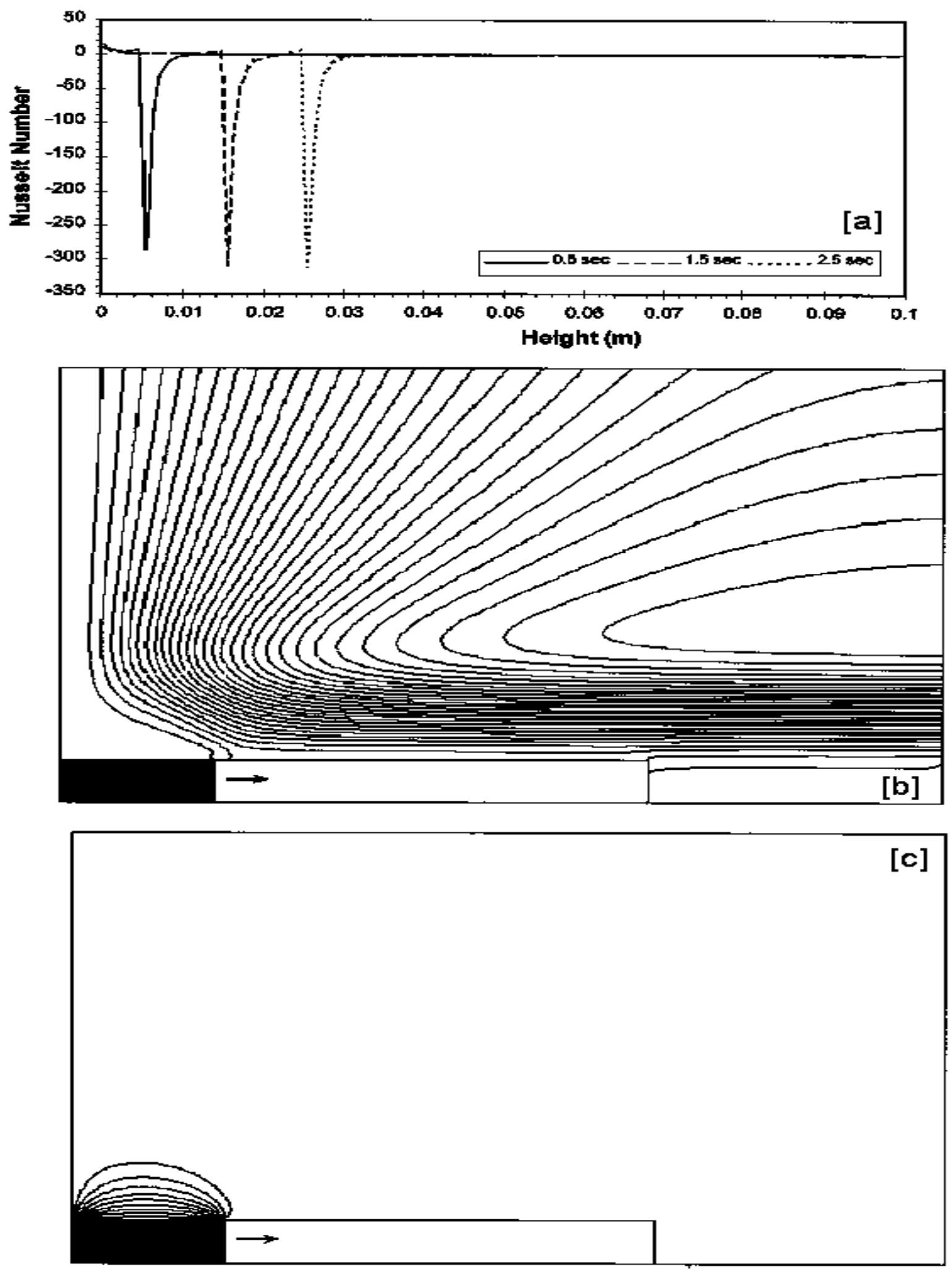

Fig 6 . $1 \mathrm{~cm} / \mathrm{s}$ comustion front velocity with no gravity [ a] Nusselt number, [b] stream function at $t=2.5 \mathrm{sec}$ and [c] temparature contours at $t=2.5 \mathrm{~s}$ 


\section{NATURAL CONVECTION AND SOLIDPHASE COMBUSTION}

\section{S. E. WHITNEY, H. J. VILJOEN.}

Chemical Engineering Communications, 190: 393 - 430, 2003 Copyright (C 2003 Taylor \& Francis
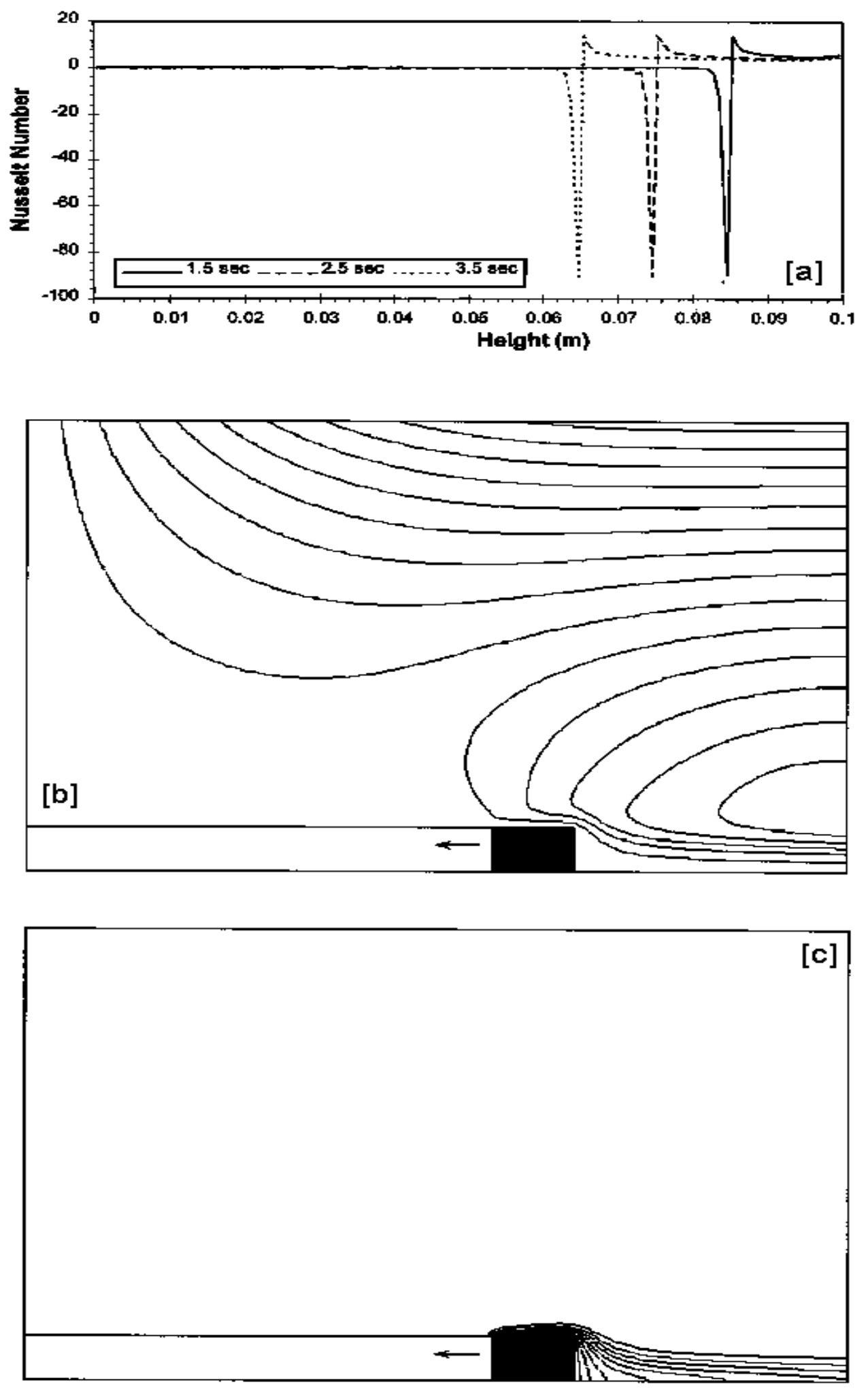

Fig $7.1 \mathrm{~cm} / \mathrm{s}$ c ombustion fro nt velocity. [a] Nusselt number, [b] stream function at t=0.3 s, and [c] tem perature conto urs at $t=0.3 \mathrm{~s}$ 


\section{NATURAL CONVECTION AND SOLIDPHASE COMBUSTION}

\section{S. E. WHITNEY, H. J. VILJOEN.}

Chemical Engineering Communications, 190: 393 - 430, 2003 Copyright (C) 2003 Taylor \& Francis

front heat flows from the cylinder into the gas phase, and the flow is directed upwards parallel to the cylinder wall. This flux is greatest at the combustion front location since the gas temperature is lowest there; the flux then decays towards the top of the cylinder as the gas temperature rises. At the combustion front location, the gas is heated quite rapidly and the pressure rises. This induces a localized circulation cell, and over a small distance ahead of the combustion front [2_3 mm] the heated gas flows past the preheating zone. Over this region, heat flows from

the preheated gas into the solid. The isotherms are quite compressed and the heat flux is high, hence the local Nusselt number is large. However, the area for heat transfer is very small in this case and the total energy that flows into the solid phase is negligible. Far ahead of the combustion front, the Nusselt number is zero since the gas temperature is the same as the wall temperature. Slow Combustion Antiparallel to Gravity. In Figure 8[a] the local Nusselt number along the cylinder wall is plotted when the combustion front propagation velocity is constant at $V f=p 1 \mathrm{~cm} / \mathrm{s}$. The Nusselt number is small positive behind the combustion front, since energy flows from the hot product zone to the gas. Coinciding with the combustion front position,

the Nusselt number changes sign; ahead of the combustion front a significant amount of energy is flowing from the gas phase to the solid phase. This is simple to explain if one considers the streamlines and temperature fields, shown in Figures 8[b] and 8[c], respectively. Near the combustion front the gas flows parallel to the wall, and ahead of the combustion front it flows more outward [i.e., a shift from axial to radial flow]. The thermal field associated with this flow confirms that the isotherms

shift from near parallel to near normal as $\mathrm{x}$ increases. The gases are heated up behind the combustion front and are advected ahead of the combustion front. Hence the temperature in the gas phase adjacent to the wall is higher than in the solid phase. Heat flows from the gas phase into the solid phase, but as the isotherms bend away from the wall, the flux component normal to the wall decreases and the local Nusselt number approaches zero further ahead of the combustion front. The torus-shaped natural convection cell center is slightly above the combustion front 


\section{NATURAL CONVECTION AND SOLIDPHASE COMBUSTION}

\section{S. E. WHITNEY, H. J. VILJOEN.}

Chemical Engineering Communications, 190: 393 - 430, 2003 Copyright (C) 2003 Taylor \& Francis

position. As time progresses, the natural convection cell develops stronger,

and the center of the torus moves up with respect to the combustion front. Therefore the flow tends to be more parallel to the cylinder, and the region over which energy flows from the gas phase into the solid phase is extended.

\section{Moderate Combustion Antiparallel to Gravity.}

The picture changes when the combustion front velocity is increased to $V_{f}=p 10 \mathrm{~cm} / \mathrm{s}$. This speed is outside the range of typical SHS values, but it is also well documented that fine powders can easily reach velocities of several $\mathrm{m} / \mathrm{s}$ [Danen and Martin, 1993]. The disparity in time scales between combustion front propagation and natural convection becomes more pronounced. The natural convection velocities are higher after $0.375 \mathrm{~s}$ compared to the case of $\mathrm{Vf}_{\mathrm{f}}=\mathrm{p} 1 \mathrm{~cm} / \mathrm{s}$, and the flow continues to develop into a stronger cell. After $1.5 \mathrm{~s}$ the absolute value of the Nusselt number is larger than in the previous case. The gas velocity parallel to the cylinder increases with propagation velocity and the thermal boundary layer is steeper. But the center of the torus seats closer to the combustion front, and the streamlines change from parallel to normal over shorter distance ahead of the combustion front. This means that the region where heat flows from the gas phase into the cylinder is reduced. The Nusselt number, stream functions, and temperature fields are shown in Figures 9[a]_[c]. Due to the disparity in time scales, the starting vortex is meta-stable. The position of the vortex oscillates around the combustion front location. The vortex initially lags the combustion front due to inertia effects. Then it gains energy from the reaction and accelerates away from the combustion front. However, it soon loses this energy to the preform, slowing the torus down so that it again lags behind the combustion front. Table I shows that these position oscillations are greatest with these moderate combustion propagation velocities. 


\section{NATURAL CONVECTION AND SOLIDPHASE COMBUSTION}

\section{S. E. WHITNEY, H. J. VILJOEN.}

Chemical Engineering Communications, 190: 393 - 430, 2003 Copyright (C) 2003 Taylor \& Francis
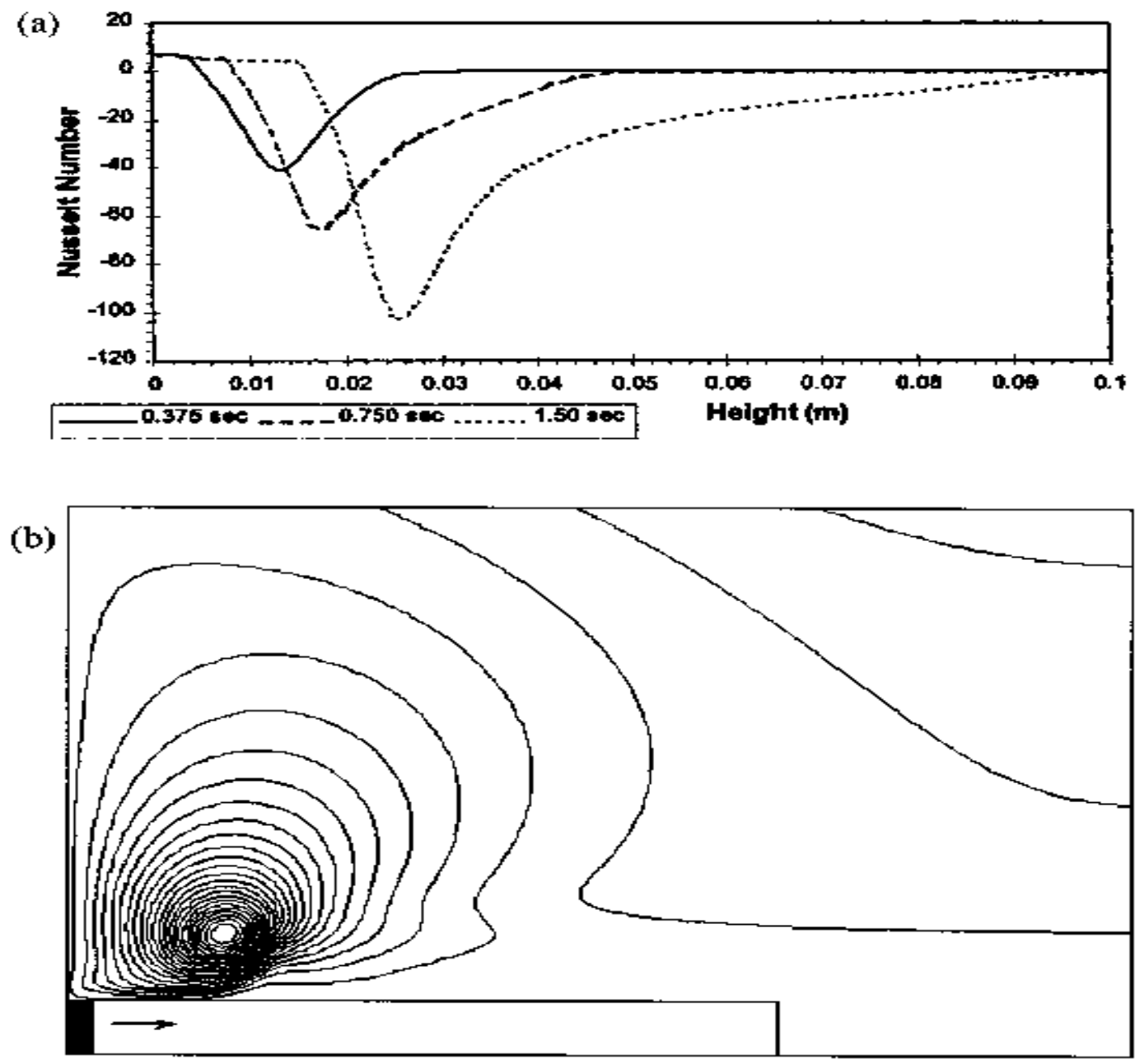

(c)

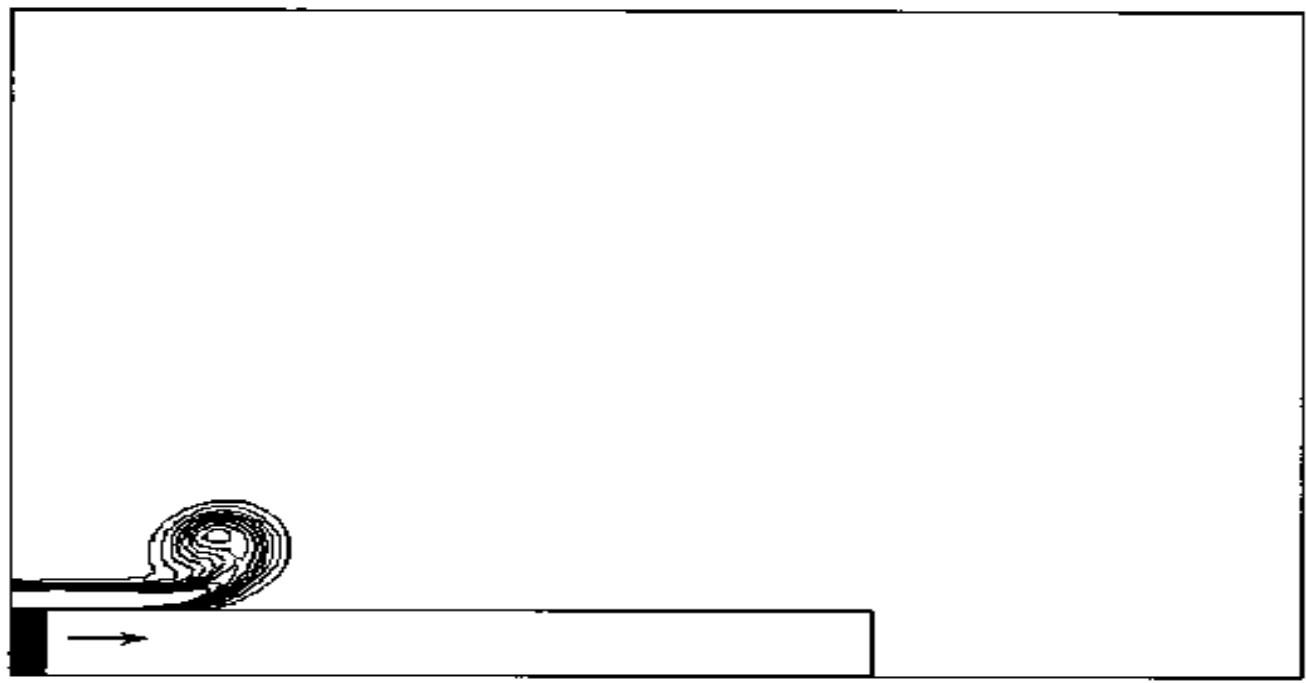

Fig 8. $1 \mathrm{~cm} / \mathrm{s}$ combustion front velocity. (a) Nusselt number, (b) stream function at $t=0.375 \mathrm{~s}$, and (c) temperature contours at $t=0.375 \mathrm{~s}$. 


\section{NATURAL CONVECTION AND SOLIDPHASE COMBUSTION}

\section{S. E. WHITNEY, H. J. VILJOEN.}

Chemical Engineering Communications, 190: 393 - 430, 2003 Copyright (C) 2003 Taylor \& Francis

In addition to position oscillations, the torus expands and contracts in the axial and radial directions. Fast Combustion Antiparallel to Gravity. When the propagation speed is $V_{f}=p 25$ $\mathrm{cm} / \mathrm{s}$ the combustion front induces such high velocities adjacent to the wall that the parallel flow becomes unstable and oscillations occur. This phenomenon is well known, spelling the onset of Tollmien- Schlichting waves [Van Dyke, 1982]. The oscillatory flow creates undulations in the isotherms, and the local Nusselt number oscillates behind the front, as shown in Figure $10[a][t=0.15 \mathrm{~s}]$. A qualitative difference in the heat transfer is observed. Heat flows from the cylinder under all circumstances, and the maximum flux is just ahead of the combustion

front. In this case the center of the torus is always lower than the position of the combustion front. Compare this to the previous two cases where the maximum heat transfer into the cylinder occurred just ahead of the combustion front. The heated gas behind the combustion front follows the streamlines as shown in Figure 10[b]. The bulk of this flow turns away from the wall before the combustion front and very little flows ahead of the combustion front. Consequently the temperature of the gas

adjacent to the preheating zone is not very high, and heat actually flows from the preheating zone to the gas phase. Further ahead of the combustion front the two phases are of course in thermal equilibrium, and the local Nusselt number becomes zero. It is evident that between $10 \mathrm{~cm} / \mathrm{s}$ and $25 \mathrm{~cm} / \mathrm{s}$ propagation velocities, the rising speed of the natural convection cell is no longer able to keep up with the combustion front. The rising speed increases with increased propagation speed until a limit is reached. The buoyancy, viscous, and inertia forces approach an equilibrium for this dynamic boundary condition [i.e., the changing thermal conditions at the wall], and qualitative differences exist in the Nusselt numbers for propagation velocities higher and lower than the natural convection limit. 


\section{NATURAL CONVECTION AND SOLIDPHASE COMBUSTION}

\section{S. E. WHITNEY, H. J. VILJOEN.}

Chemical Engineering Communications, 190: 393 - 430, 2003 Copyright (C) 2003 Taylor \& Francis

(a)

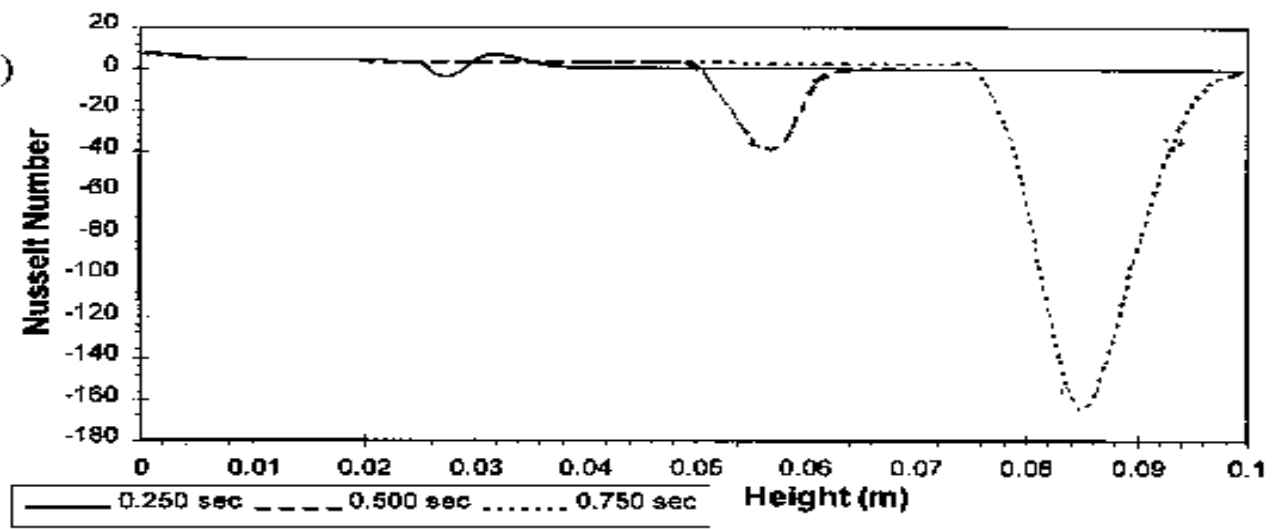

(b)

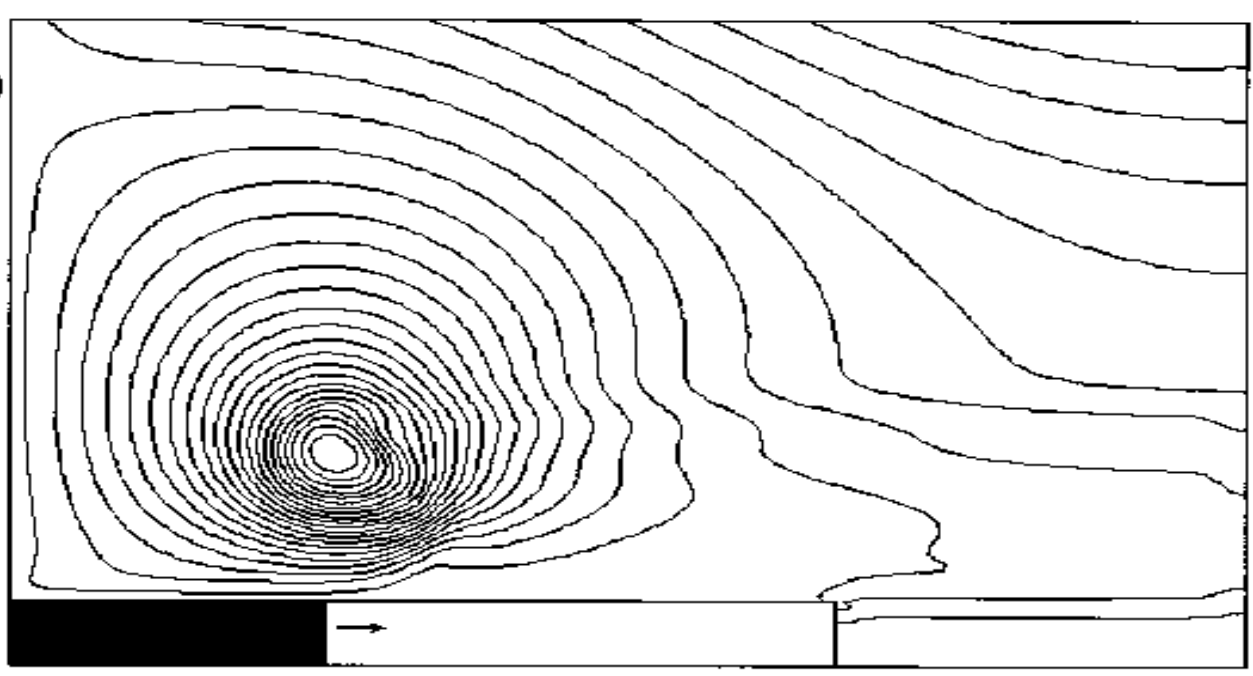

(c)

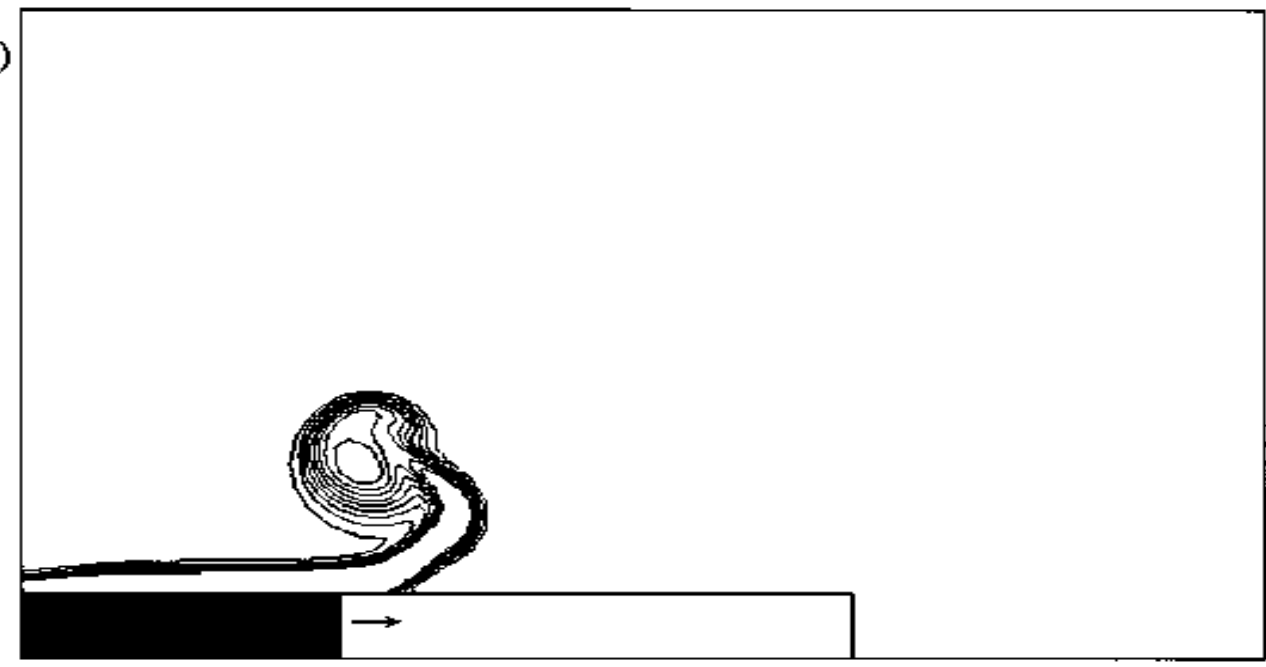

Fig 9. $10 \mathrm{~cm} / \mathrm{s}$ combustion front velocity. (a) Nusselt number, (b) stream function at $t=0.375 \mathrm{~s}$, and (c) temperature contours at $t=0.375 \mathrm{~s}$. 


\section{NATURAL CONVECTION AND SOLIDPHASE COMBUSTION}

\section{S. E. WHITNEY, H. J. VILJOEN.}

Chemical Engineering Communications, 190: 393 - 430, 2003 Copyright (C) 2003 Taylor \& Francis

(a)

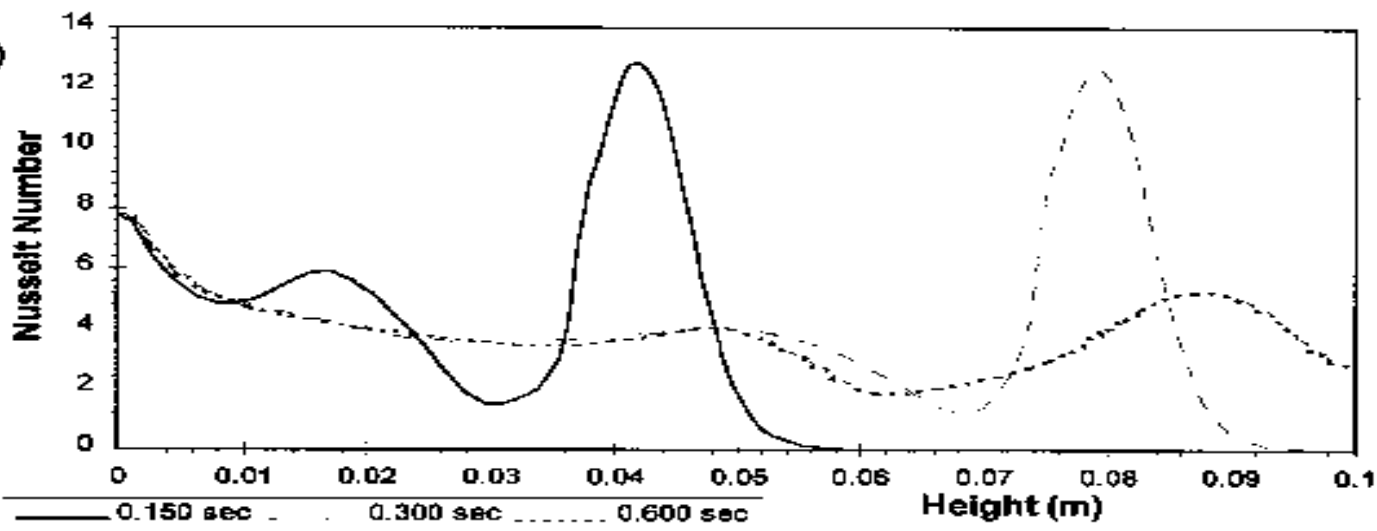

(b)

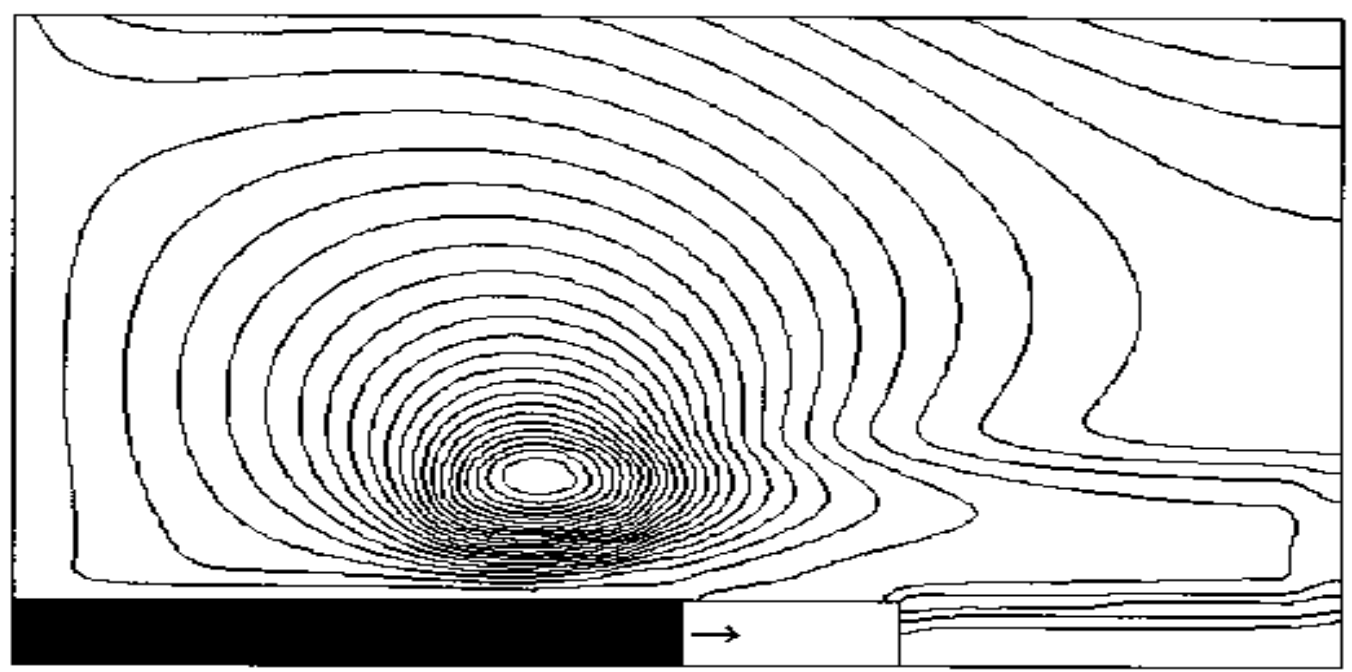

(c)

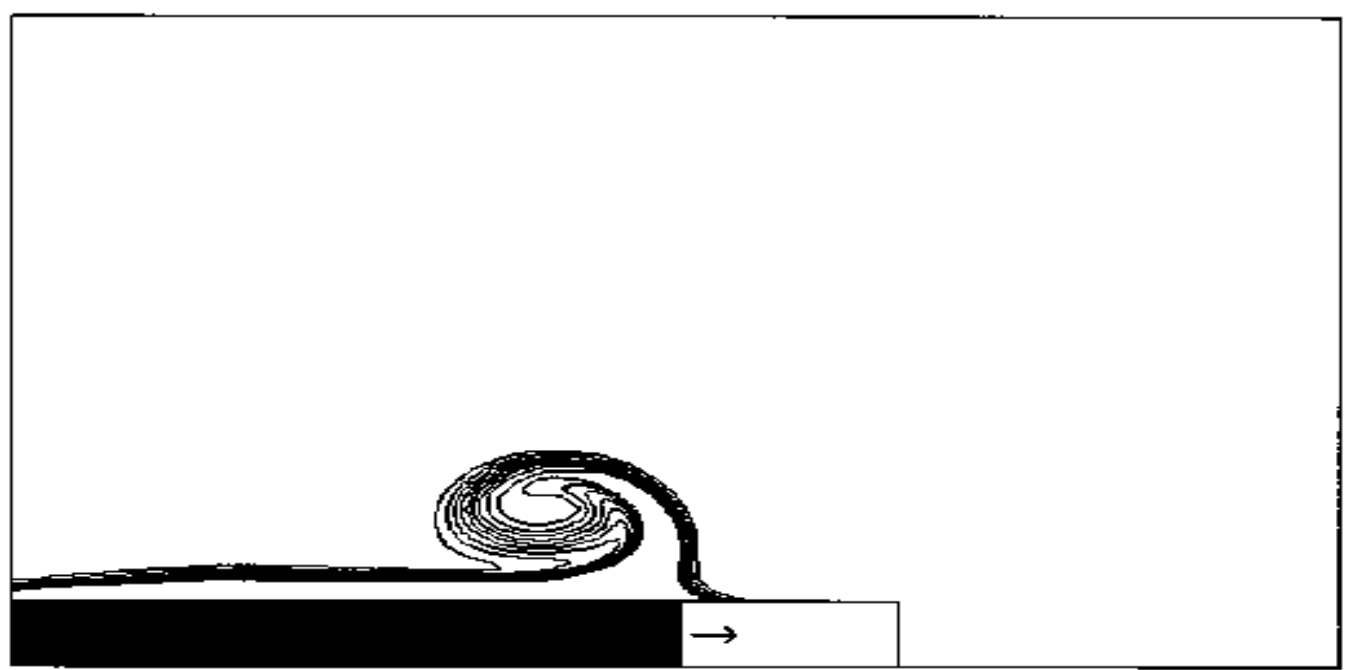

Fig 10. $25 \mathrm{~cm} / \mathrm{s}$ combustion front velocity. (a) Nusselt number, (b) stream function at $t=0.3 \mathrm{~s}$, and (c) temperature contours at $t=0.3 \mathrm{~s}$. 


\section{NATURAL CONVECTION AND SOLIDPHASE COMBUSTION}

\section{S. E. WHITNEY, H. J. VILJOEN.}

Chemical Engineering Communications, 190: 393 - 430, 2003 Copyright (C) 2003 Taylor \& Francis

Oscillating Combustion Front Velocities

The combustion front was also studied with a sinusoidal velocity, where the amplitude of combustion oscillations is smaller than the mean velocity,

$V_{c}=V_{f}+V_{a} \sin (f t)$

This sinusoidal velocity occurs when the combustion time scale is small compared to the conduction time scale. The combustion slows until enough energy has conducted to preheat the adjacent unreacted solids, then the combustion velocity increases and the cycle repeats. Sivashinsky [1981] analyzed the stability of steady propagating fronts and found conditions where the planar as well as rotating oscillations can occur. As described above, torus oscillations are magnified when the torus is located at the same position as the combustion front; thus the effect of

combustion front oscillations was studied with a mean combustion propagation of $10 \mathrm{~cm} / \mathrm{s}$. The magnitude of this effect depends on the frequency of combustion front oscillations. At high frequencies, the inertia of the torus dampens out any potential effect from the combustion oscillations. At low frequencies, the torus is relatively unaffected by the slow changes in the combustion propagation. Therefore, the effect is maximized with moderate combustion front frequencies, and $f=10 p$ was studied. For simplicity, only positive values of the velocity amplitude, $\mathrm{Va}$,

are considered. When the combustion front velocity is constant, the torus moves in oscillations as shown in Figure 5 and Table I. Let_xc denote the torus axial position from the ignited cylinder end for a constant combustion front velocity. When the combustion front has a sinusoidal velocity, the torus position [denoted _xs] is affected as additional oscillations are superimposed on the gas flow. Figure 11 shows this shift in torus position, Xs - Xc. The shift is zero for $t<0: 05 \mathrm{~s}$ as the torus still must overcome its inertia. The axial position of the sinusoidal combustion front is equal to or greater than the constant combustion front posi- 


\section{NATURAL CONVECTION AND SOLIDPHASE COMBUSTION}

\section{S. E. WHITNEY, H. J. VILJOEN.}

Chemical Engineering Communications, 190: 393 - 430, 2003 Copyright (C) 2003 Taylor \& Francis

tion. Thus for $0: 05 \mathrm{~s}<\mathrm{t}<0: 35 \mathrm{~s}$, the sinusoidal torus rises faster than the constant torus due to the extra initial energy supplied by the cylinder. A typical combustion front velocity is also shown in Figure 11. Immediately after the velocity reaches its maximum [at $t=0.15 \mathrm{~s}$, $0.35 \mathrm{~s}, 0.55 \mathrm{~s}$ ], the position shift grows due to the extra energy supplied. After the combustion front velocity reaches its minimum [at $t=0.05 \mathrm{~s}, 0.25 \mathrm{~s}, 0.45 \mathrm{~s}$, ], the position shift declines toward zero since relatively less energy has been released by the cylinder. Therefore the shift, $\mathrm{Xs}-\mathrm{Xc}$, is sinusoidal for $\mathrm{t}>0: 35 \mathrm{~s}$ with a frequency that is equal to the frequency of the sinusoidal combustion front velocity. These effects are directly proportional to the combustion front velocity amplitude. In Figure 11 , the position shift is larger for $V_{a}=7: 5 \mathrm{~cm} / \mathrm{s}$ than with $V_{a}=5: 0 \mathrm{~cm} / \mathrm{s}$. These torus shift oscillations are superimposed on the torus oscillations shown for the constant combustion velocity cases. The two sets of oscillations do not appear to interact. Thus the Nusselt number figures above are qualitatively the same with sinusoidal combustion. Two quantitative effects are seen: the position of the maximum Nusselt number moves sinusoidally at a frequency, $f$, and the maximum value of the Nusselt number increases sinusoidally at the frequency, $f$. There are a few things to note in Figure 11. At $t=0: 7 \mathrm{~s}$ in Figure 11, the position shift peak is small due to the torus reaching the end of the Figure 11. Difference in torus position between oscillating combustion front velocity and constant combustion front velocity at $10 \mathrm{~cm} / \mathrm{s}$. Two cases are shown with amplitudes of $5.0 \mathrm{~cm} / \mathrm{s}$ and $7.5 \mathrm{~cm} / \mathrm{s}$. cylinder [10 cm]. When CFD calculations were made with longer cylinders

or with higher frequency oscillations, the position shifts continue to oscillate with equal magnitude. Secondly, the location of the torus center, _xs and _xc, was interpolated from data on a finite-sized grid. When these two interpolated locations are subtracted, error builds, resulting in the jaggedness of the shift shown in Figure 11. 


\section{NATURAL CONVECTION AND SOLIDPHASE COMBUSTION}

\section{S. E. WHITNEY, H. J. VILJOEN.}

Chemical Engineering Communications, 190: 393 - 430, 2003 Copyright (C) 2003 Taylor \& Francis

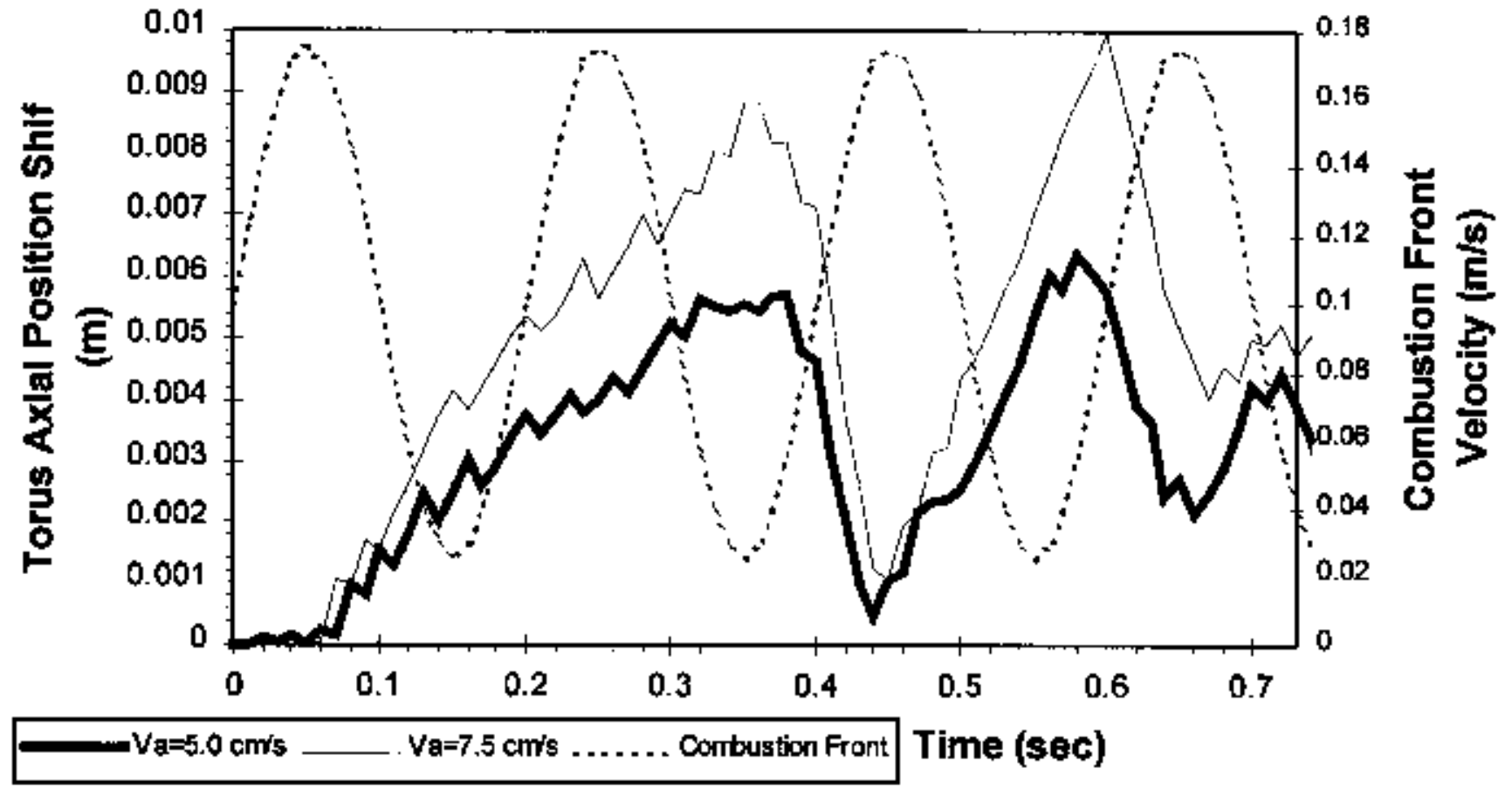

Fig 11. Difference in torus position between oscillating combustion front velocity and constant combustion front velocity at $10 \mathrm{~cm} / \mathrm{s}$. Two cases are shown with amplitudes of $5.0 \mathrm{~cm} / \mathrm{s}$ and $7.5 \mathrm{~cm} / \mathrm{s}$.

\section{ANALYTICAL COMPARISONS TOCFDRESULTS}

Computational fluid dynamics calculations must be validated. If the governing equations used were incorrect or if the solution was not grid independent, then the results from CFD calculations cannot be trusted. Thus two analytical solutions are developed that describe the Nusselt number when preheating is observed [slow combustion front velocity]. Both analytical solutions closely match the CFD results, thus verifying them. These can also be used to extend the CFD results to alternative combustion conditions. Self-Similar Flat Plate and Leveque Approximation The first analysis treats the cylinder as a flat surface; this is a rather extreme assumption because the curvature of the cylinder is not negligible. But the problem lends itself to the Leveque approximation for the velocity profile, and the solution of the self-similar problem is routine. The steady-state energy equation including convection in $\mathrm{x}$ direction [axial] and conduction in y direction [radial] is: 


\section{NATURAL CONVECTION AND SOLIDPHASE COMBUSTION}

\section{S. E. WHITNEY, H. J. VILJOEN.}

Chemical Engineering Communications, 190: 393 - 430, 2003 Copyright (C) 2003 Taylor \& Francis

$$
k \frac{\partial^{2} T}{\partial y^{2}}-\rho C_{p} u \frac{\partial T}{\partial x}=0
$$

Assume a velocity profile in the $x$ direction of the form

$u=a y^{p}$

and assume the incoming gas has been heated to the adiabatic combustion temperature, Tw. The Leveque gas velocity was estimated by the velocity near the cylinder calculated by Fluent. These velocities were:[a $=0: 5 m=s ; p=0]$, theoretically valid for low Prandtl numbers with a small velocity boundary layer, $\operatorname{Pr} \_1 ;[a=15: 54 m 1=2=s ; p=0: 5]$, the best fit of the Fluent-calculated velocity; and [ $a=413: 2=s ; p=1]$, theoretically valid for high Prandtl numbers with a small thermal boundary layer, $\operatorname{Pr} 1$.

Thus, the energy balance becomes:

The boundary conditions are: at $y=0$ and as $x ! 1$ [thus $Z=0$ ], $\mathrm{T}=\mathrm{To}_{0}$ and as $\mathrm{y} ! 1$ and at $\mathrm{x}=0$ [thus $\left.\mathrm{Z} ! 1\right], T=T w$. Define a dimensionless temperature that ranges from 0 to 1 at these boundaries:

$$
0(T)=\frac{T-T_{o}}{T_{w}-T_{o}} \quad \frac{T}{x}=0
$$

Dimensionless lengths will be defined with respect to the cylinder radius. While the flat Leveque solution doesn't have a radius, it will be used to compare with the CFD results and the cylindrical solution derived below: 


\section{NATURAL CONVECTION AND SOLIDPHASE COMBUSTION}

\section{S. E. WHITNEY, H. J. VILJOEN.}

Chemical Engineering Communications, 190: 393 - 430, 2003 Copyright (C 2003 Taylor \& Francis

$$
x^{\prime}=\frac{x}{r_{0}}
$$

And

$$
y^{\prime}=\frac{y}{r_{0}}
$$

Also define the self-similarity transformation $\mathrm{Z}, \mathrm{T}=\mathrm{T}+\mathrm{ZP}$, where $\mathrm{Z}$ is defined as

$$
\eta=\beta\left(x^{\prime}\right)^{m}\left(y^{\prime}\right)^{n}
$$

Set $\mathrm{n}=1$ and substitute in Equation [3]:

$$
\begin{aligned}
& \frac{\partial^{2} 0}{\partial \eta^{2}}=\frac{m}{\kappa \beta^{p+2}} \frac{\eta^{p+1}}{\left(\alpha^{\prime}\right)^{m(p+2)+1}} \frac{\partial 0}{\partial \eta} \\
& \kappa=\frac{k}{\rho C_{p} a r_{0}^{p+1}}
\end{aligned}
$$

Where

It follows that $m=\_1 \mathrm{pp} 2$ maintains the self-similarity. Define the constant, $\mathrm{b}$, to simplify the equation, $\mathrm{b}_{-}+1 / 2 \mathrm{p}$ p 2_2kp_ $1 \mathrm{pp} 2$ and Equation [4] is written as follows:

$$
\beta \equiv\left([p+2]^{2} \kappa\right)^{\frac{-1}{p+2}}
$$




\section{NATURAL CONVECTION AND SOLIDPHASE COMBUSTION}

\section{S. E. WHITNEY, H. J. VILJOEN.}

Chemical Engineering Communications, 190: 393 - 430, 2003 Copyright (C 2003 Taylor \& Francis

Integrating Equation [5] twice one finds $\mathrm{y}=\mathrm{Rz}$

$$
\theta=\frac{\int_{0}^{\eta} e^{-\eta^{p+2}} d \eta}{\int_{0}^{\infty} e^{-\eta^{p+2}} d \eta}
$$

This integral is quite similar to the error function,

$\operatorname{erf}(x)=\int_{0}^{x} e^{-x^{2}} d x$. The integral in the denominator can be solved numerically, defined as int. For example, when $p=1$,

$$
\theta_{\mathrm{int}}=\int_{0}^{\infty} e^{-\eta^{3}} d \eta=0.89298
$$

At small values of Z, the top integral in Equation [6] can be greatly simplified. With less than $10 \%$ error,

$$
\begin{aligned}
& e^{-\eta^{p+2}} \cong 1 \text { when } \eta \leq 10^{\frac{-1}{p+2}} \\
& \int_{0}^{\eta=\text { small }} e^{-\eta^{p+2}} d \eta \cong \int_{0}^{\eta} d \eta=\eta
\end{aligned}
$$

and

Small values of $\mathrm{Z}$ occur in two locations: gas near the surface [small yo] and gas far from the combustion front [large $x_{0}$ ]. In these regions, the gas temperature is given by 


\section{NATURAL CONVECTION AND SOLIDPHASE COMBUSTION}

\section{S. E. WHITNEY, H. J. VILJOEN.}

Chemical Engineering Communications, 190: 393 - 430, 2003 Copyright (C 2003 Taylor \& Francis

$$
0=\frac{\eta}{\theta_{\mathrm{int}}}=\left([p+2]^{2} \kappa x^{\prime}\right)^{\frac{-1}{p+2}} \frac{y^{\prime}}{\theta_{\mathrm{int}}}
$$

which holds true everywhere near the solid surface except at the singularity $x_{0}=0$. As $x_{0} ! 1$, the gas cools back to its original temperature, all the heat removed from the hot surface is eventually redeposited onto the cold surface. This analytical solution is compared to the CFD result for heat transfer at the surface, yo $=0$. From Equation [6], the heat transfer in the y direction is

$$
\begin{aligned}
q_{g} & =-k \frac{\partial T}{\partial y}=-k\left(\frac{\partial T}{\partial 0} \frac{\partial 0}{\partial \eta} \frac{\partial \eta}{\partial y^{\prime}} \frac{\partial y^{\prime}}{\partial y}\right) \\
& =\frac{k\left(T_{o}-T_{w}\right) e^{-r^{p+2}}}{\theta_{\mathrm{int}}}\left([p+2]^{2} \kappa r_{0}^{p+2} x^{\prime}\right)^{\frac{-1}{p+2}}
\end{aligned}
$$

At the $y=0$ boundary, the small $Z$ approximation will hold, thus the equation above simplifies,

$$
q_{g}=\frac{k\left(T_{o}-T_{w}\right)}{0_{\mathrm{int}}}\left([p+2]^{2} \kappa r_{0}^{p+2} x^{\prime}\right)^{\frac{-1}{p+2}}
$$

The predicted Nusselt number from the Leveque approximation is

$$
\mathrm{Nu}=\frac{1}{0_{\text {int }}} \frac{\left(T_{o}-T_{w}\right)}{\left(T_{o}-T_{\text {ref }}\right)}\left([p+2]^{2} \kappa x^{\prime}\right)^{\frac{-1}{p+2}}
$$




\section{NATURAL CONVECTION AND SOLIDPHASE COMBUSTION}

\section{S. E. WHITNEY, H. J. VILJOEN.}

Chemical Engineering Communications, 190: 393 - 430, 2003 Copyright @ 2003 Taylor \& Francis

Figure 12 shows the Nusselt number comparison between the Leveque solutions and a Fluent CFD solution. Two differences can be seen between the CFD and Leveque solutions:

1. The CFD calculations used a temperature profile with preheating,

Figure 1 . The majority of the preheating was in the first $1 \mathrm{~cm}$ ahead of the combustion front. Thus as $\mathrm{x}_{0} ! \mathrm{0}, \mathrm{Nu} ! 0$. The Leveque solution assumed a discontinuous temperature at $\mathrm{x}_{0}=$ 0 ; thus, the Nusselt number is infinite at the combustion front.

2. The Fluent-calculated Nusselt number is smaller negative than the Leveque solution. The Leveque approximation assumed steady-state flow: the hot surface is infinitely long. The CFD calculations are with a finite length cylinder; as time progresses, the gas passes over extended lengths of the cylinder. Due to this finite length, the CFD calculated Nusselt number is smaller negative than a full steady-state calculation: Figure 8[a] shows this Nusselt number development. The CFD solution in Figure 12 was calculated with $30 \mathrm{~cm}$ cylinder [much longer than the $10 \mathrm{~cm}$ cylinder used above] to reduce this cylinder length effect. 


\section{NATURAL CONVECTION AND SOLIDPHASE COMBUSTION}

\section{S. E. WHITNEY, H. J. VILJOEN.}

Chemical Engineering Communications, 190: 393 - 430, 2003 Copyright (C 2003 Taylor \& Francis

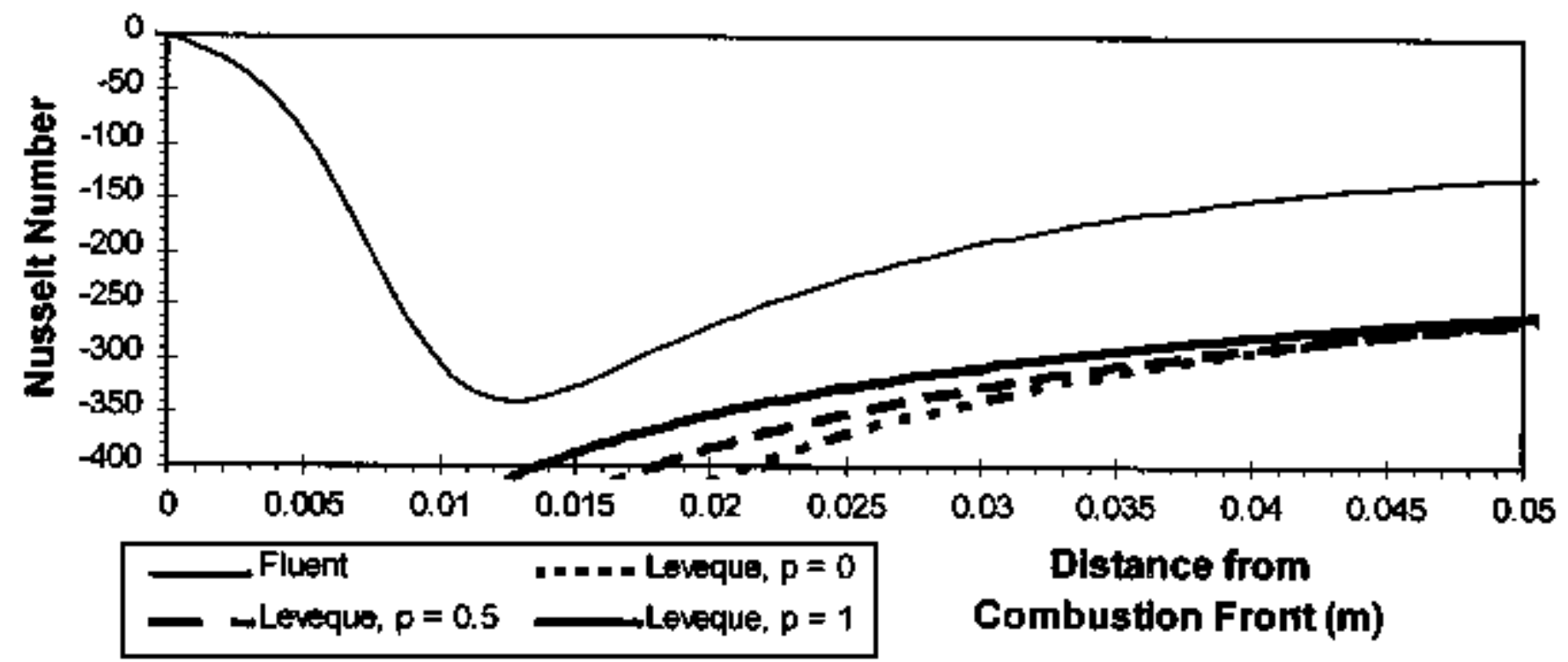

Fig 12. Comparison of fully developed Leveque solution to Fluent solutions at three different times.

Cylindrical Approximation

A second analytical solution for the Nusselt number for slow, constant combustion front velocities is presented here. The Leveque solution is adequate when the wall temperature is constant; this solution allows the exponential boundary condition, Equation [1]. Also, the flat plate approximation is dropped. Thus the solution will be more accurate, but also more complex. The steady-state energy equation, including convection in $\mathrm{x}$ direction and conduction in $r$ direction, for axisymmetric cylindrical flow is: $k$

$k\left(\frac{\partial^{2} T}{\partial r^{2}}+\frac{1}{r} \frac{\partial T}{\partial r}\right)-\rho C_{p} u \frac{\partial T}{\partial x}=0$

with the boundary conditions 


\section{NATURAL CONVECTION AND SOLIDPHASE COMBUSTION}

\section{S. E. WHITNEY, H. J. VILJOEN.}

Chemical Engineering Communications, 190: 393 - 430, 2003 Copyright (C) 2003 Taylor \& Francis

1) at $r=\mathrm{I}_{0}: \quad T=T_{0}+\left(T_{1 w}-T_{0}\right) e^{-500 x}$ wilh $x$ measured in meters.

2) at $r=2 r_{0}, \frac{\partial T}{\partial r}=0$, and

3) at $x=0, \quad T=T_{\mathrm{ln}}$.

The second boundary condition is somewhat arbitrary; the distance, 2ro, was chosen since it is outside the thermal boundary layer. Define a dimensionless temperature that ranges from 0 to 1 at these boundaries:

$$
0(T)=\frac{T-T_{o}}{T_{w}-T_{o}}
$$

as well as a dimensionless radius,

$$
r=\frac{r}{r_{0}}
$$

Define the gas velocity,

$\mathrm{u}=\operatorname{arp}$

$$
\frac{\partial^{2} \theta}{\partial r^{\prime 2}}+\frac{1}{r^{\prime}} \frac{\partial \theta}{\partial r^{\prime}}-\frac{\left(r^{\prime}\right)^{p}}{\kappa} \frac{\partial \theta}{\partial x^{\prime}}=0
$$

so,

Let the dimensionless temperature be the sum of an infinite series of solutions for the energy balance, 


\section{NATURAL CONVECTION AND SOLIDPHASE COMBUSTION}

\section{S. E. WHITNEY, H. J. VILJOEN.}

Chemical Engineering Communications, 190: 393 - 430, 2003 Copyright (C 2003 Taylor \& Francis

So, the energy equation for the ith solution becomes:

$$
0=\sum_{i=1}^{\infty} f_{i}\left(r^{\prime}\right) e^{-\beta_{j} x^{2}}
$$

So the energy equationnto the tth solution becomes

$$
e^{-\beta_{i} x^{\prime}} f_{i}^{\prime \prime}(r)+\frac{1}{r^{\prime}} e^{-\beta_{j} x^{\prime}} f^{\prime}\left(r^{\prime}\right)+\frac{\beta_{i}}{k}(r){ }^{p} e^{-\beta_{j}-x_{i}} f_{i}(r)=0
$$

Multiply by

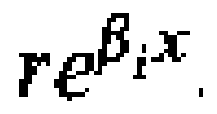

The function, fitrop, is an unknown polynomial:

Substituting this polynomial into the energy Equation [8] and xpanding in powers of $r$ ':

$$
\begin{aligned}
& r^{\prime} f_{i}^{\prime \prime}\left(r^{\prime}\right)+f_{i}^{\prime}\left(r^{\prime}\right)+\frac{\beta_{i}}{\kappa}\left(r^{\prime}\right)^{p+1} f_{i}\left(r^{\prime}\right)=0 \\
& \left\{\begin{array}{l}
\left.\left[1^{2} C_{1, i}\right]\left(r^{\prime}\right)^{0}+\left[2^{2} C_{2, i}\right]\left(r^{\prime}\right)^{1}+\left[3^{2} C_{3, i}\right]\left(r^{\prime}\right)^{2}+\left[4^{2} C_{4, i}\right]\left(r^{\prime}\right)^{3}+\cdots+\right) \\
{\left[C_{0, i}\left(\frac{\beta_{i}}{\kappa}\right)\right]\left(r^{\prime}\right)^{p+1}+\left[C_{1, i}\left(\frac{\beta_{i}}{\kappa}\right)\right]\left(r^{\prime}\right)^{p+2}+\left[C_{2, i}\left(\frac{\beta_{i}}{\kappa}\right)\right]\left(r^{\prime}\right)^{p+3}+\cdots}
\end{array}\right\}=0
\end{aligned}
$$

Grouping like powers of $\mathrm{r}$, it is seen that the above equation will give nonzero coefficients only if $p$ is an integer. If $\mathrm{C}_{0 ; i}=0$, then the solution is trivial; every constant would be zero. Thus 
NATURAL CONVECTION AND SOLIDPHASE COMBUSTION

\section{S. E. WHITNEY, H. J. VILJOEN.}

Chemical Engineering Communications, 190: 393 - 430, 2003 Copyright (C) 2003 Taylor \& Francis

$$
\begin{gathered}
C_{0, i} \neq 0 \\
C_{p+2, i}=C_{0, i} \frac{-1}{(p+2)^{2}}\left(\frac{\beta_{i}}{\kappa}\right) \\
C_{2(p+2), i}=C_{0, i} \frac{1}{2^{2}(p+2)^{4}}\left(\frac{\beta_{i}}{\kappa}\right)^{2} \text { and } \\
C_{n(p+2), i}=C_{0, i} \frac{(-1)^{n}}{(p+2)^{2 n}(n !)^{2}}\left(\frac{\beta_{i}}{\kappa}\right)^{n} \\
=C_{0, i} \frac{(-1)^{n}}{(2)^{2 n}(n !)^{2}}\left[\left(\frac{4 \beta_{i}}{[p+2]^{2} \kappa}\right)^{1 / 2}\right]^{2 n}
\end{gathered}
$$

where $n=0,1,2,3, \ldots$ and all other constants are zero. Thus,

$$
f_{i}\left(r^{\prime}\right)=\sum_{m=0}^{\infty} C_{m, i}\left(r^{\prime}\right)^{m}=\sum_{n=0}^{\infty} C_{0, i} \frac{(-1)^{n}\left[\left(\frac{4 \beta_{i}}{p+2]^{2} \kappa}\right)^{1 / 2}\right]^{2 n}\left(r^{\prime}\right)^{n(p+2)}}{(2)^{2 n}(n !)^{2}}
$$

Define

$$
z_{i}\left(r^{\prime}\right)=\gamma_{i}\left(r^{\prime}\right)^{\frac{p+2}{2}}
$$

where

$$
\gamma_{i}=\left(\frac{4 \beta_{i}}{[p+2]^{2} \kappa}\right)^{1 / 2}
$$

Then $f_{i}(r)$ simplifies to a Bessel function of the first kind of order zero,

$$
f_{i}\left(r^{\prime}\right)=C_{0, i} \sum_{m=0}^{\infty} \frac{(-1)^{n}\left[z_{i}\left(r^{\prime}\right)\right]^{2 n}}{(2)^{2 n}(n !)^{2}}=C_{0, i} J_{0}\left[z_{i}\left(r^{\prime}\right)\right]
$$


NATURAL CONVECTION AND SOLIDPHASE COMBUSTION

\section{S. E. WHITNEY, H. J. VILJOEN.}

Chemical Engineering Communications, 190: 393 - 430, 2003 Copyright (C 2003 Taylor \& Francis

The function $J_{0}\left[z_{i}\left(r^{\prime}\right)\right]$ satisfies Equation (8), so the Bessel function of the second kind of order zero, $Y_{0}\left[z_{i}\left(r^{\prime}\right)\right]$, is also a solution. Thus a general solution is:

$$
f_{i}\left(r^{\prime}\right)=C_{0, i} J_{0}\left[z_{i}\left(r^{\prime}\right)\right]+D_{0, i} Y_{0}\left[z_{i}\left(r^{\prime}\right)\right]
$$

The dimensionless temperature becomes

$$
0=\sum_{i=1}^{\infty}\left(C_{0, i} J_{0}\left[z_{i}\left(r^{\prime}\right)\right]+D_{0, i} Y_{0}\left[z_{i}\left(r^{\prime}\right)\right]\right) e^{-\beta_{i} x^{\prime}}
$$

From the first boundary condition, $O\left(r_{0}\right)=e^{-500 r_{0} x^{\prime}}$ for all values of $i$. A particular solution will be added to satisfy this boundary condition:

$$
\begin{aligned}
& O_{p}\left(r_{0}\right)=\left(C J_{0}\left[\gamma r_{0}^{p+2}\right]+D Y_{0}\left[\gamma r_{0}^{\frac{p+2}{2}}\right]\right) e^{-500 r_{0} \cdot x^{\prime}}=e^{-500 r_{0} x^{\prime}} \\
& \text { where } \gamma=\left(\frac{2000}{[p+2]^{2} \kappa}\right)^{1 / 2} \text { using SI units. }
\end{aligned}
$$

Thus

$$
\begin{aligned}
& 0=\sum_{i=1}^{\infty}\left(C_{0, i} J_{0}\left[z_{i}\left(r^{\prime}\right)\right]+D_{0, i} Y_{0}\left[z_{i}\left(r^{\prime}\right)\right]\right) e^{-\beta_{i} x^{\prime}} \\
& +\left(C J_{0}\left[\gamma\left(r^{\prime} r_{0}\right)^{\frac{p+2}{2}}\right]+D Y_{0}\left[\gamma\left(r^{\prime} r_{0}\right)^{\frac{p+2}{2}}\right]\right) e^{-500 r_{0}}
\end{aligned}
$$

Since $C \neq 0, C_{0, i} \neq 0, D \neq 0, D_{0, i} \neq 0$, and $e^{-\beta_{j} x^{3}} \neq 0$

$$
0=C_{0, i} J_{0}\left[z_{i}\left(r_{0}\right)\right]+D_{0, i} Y_{0}\left[z_{i}\left(r_{0}\right)\right]
$$

and

$$
1=C J_{0}\left[\gamma r_{0}^{\frac{p+2}{2}}\right]+D Y_{0}\left[\gamma r_{0}^{\frac{p+2}{2}}\right]
$$

The second boundary condition is needed to solve for the unknown coefficients. Beyond the thermal boundary layer, assumed at $r^{\prime}=2$, there 
NATURAL CONVECTION AND SOLIDPHASE COMBUSTION

\section{S. E. WHITNEY, H. J. VILJOEN.}

Chemical Engineering Communications, 190: 393 - 430, 2003 Copyright (C) 2003 Taylor \& Francis are no radial gradients:

$$
\left.\frac{d 0}{d r^{\prime}}\right|_{r^{\prime}=2}=\left.\left\{\begin{array}{c}
\sum_{i=1}^{\infty}-\frac{p+2}{2} \gamma_{i}\left(r^{\prime}\right)^{\frac{p}{2}}\left(C_{0, i} J_{1}\left[z_{i}\left(r^{\prime}\right)\right]+D_{0, i} Y_{1}\left[z_{i}\left(r^{\prime}\right)\right]\right) e^{-\beta_{i} x} \\
-\gamma^{\frac{p+2}{2}} r_{0}^{\frac{p+2}{2}}\left(r^{\prime}\right)^{\frac{p}{2}}\left(C J_{1}\left[\gamma\left(r^{\prime} r_{0}\right)^{\frac{p+2}{2}}\right]+D Y_{1}\left[\gamma\left(r^{\prime} r_{0}\right)^{\frac{p+2}{2}}\right]\right) e^{-500 x}
\end{array}\right\}\right|_{r^{\prime}=2}=0
$$

Thus,

$$
C J_{1}\left[\gamma\left(2 r_{0}\right)^{\frac{p+2}{2}}\right]+D Y_{1}\left[\gamma\left(2 r_{0}\right)^{\frac{p+2}{2}}\right]=0
$$

and $C_{0, i} J_{1}\left[z_{i}(2)\right]+D_{0, i} Y_{1}\left[z_{i}(2)\right]=0$.

Combining with Equation (9), the following linear systems result:

$$
\left[\begin{array}{cc}
J_{0}\left[\gamma r_{0}^{\frac{p+2}{2}}\right] & Y_{0}\left[\gamma r_{0}^{\frac{p+2}{2}}\right] \\
J_{1}\left[\gamma\left(2 r_{0}\right)^{\frac{p+2}{2}}\right] & Y_{1}\left[\gamma\left(2 r_{0}\right)^{\frac{p+2}{2}}\right]
\end{array}\right]\left[\begin{array}{l}
C \\
D
\end{array}\right]=\left[\begin{array}{l}
1 \\
0
\end{array}\right]
$$

and $\left[\begin{array}{cc}J_{0}\left[z_{i}\left(r_{0}\right)\right] & Y_{0}\left[z_{i}\left(r_{0}\right)\right] \\ J_{1}\left[z_{i}\left(2 r_{0}\right)\right] & Y_{1}\left[z_{i}\left(2 r_{0}\right)\right]\end{array}\right]\left[\begin{array}{c}C_{0, i} \\ D_{0, i}\end{array}\right]=\left[\begin{array}{l}0 \\ 0\end{array}\right]$

Since $\gamma$ is known, Equation (10a) can be used to solve for $C$ and $D$ :

$$
C=\frac{Y_{1}\left[\gamma\left(2 r_{0}\right)^{\frac{p+2}{2}}\right]}{J_{0}\left[\gamma r_{0}^{\frac{p+2}{2}}\right] Y_{1}\left[\gamma\left(2 r_{0}\right)^{\frac{p+2}{2}}\right]-J_{1}\left[\gamma\left(2 r_{0}\right)^{\frac{p+2}{2}}\right] Y_{0}\left[\gamma r_{0}^{\frac{p+2}{2}}\right]}
$$

and

$$
D=\frac{-J_{1}\left[\gamma\left(2 r_{0}\right)^{\frac{p+2}{2}}\right]}{J_{0}\left[\gamma_{0}^{\frac{p+2}{2}}\right] Y_{1}\left[\gamma\left(2 r_{0}\right)^{\frac{p+2}{2}}\right]-J_{1}\left[\gamma\left(2 r_{0}\right)^{\frac{p+2}{2}}\right] Y_{0}\left[\gamma r_{0}^{\frac{p+2}{2}}\right]}
$$




\section{NATURAL CONVECTION AND SOLIDPHASE COMBUSTION}

\section{S. E. WHITNEY, H. J. VILJOEN.}

Chemical Engineering Communications, 190: 393 - 430, 2003 Copyright (C) 2003 Taylor \& Francis

The determinant of the left matrix of Equation (10b) must be zero for the existence of nonzero coefficients. So,

$$
J_{0}\left[z_{i}\left(r_{0}\right)\right] Y_{1}\left[z_{i}\left(2 r_{0}\right)\right]-J_{1}\left[z_{i}\left(2 r_{0}\right)\right] Y_{0}\left[z_{i}\left(r_{0}\right)\right]=0
$$

Table II lists the first six roots of this function, $z_{i}\left(r_{0}\right)$, found numerically. Thus

$$
\beta_{i}=\frac{\kappa}{4} \gamma_{i}^{2}(p+2)^{2}=\frac{\kappa\left[z_{i}\left(r_{0}\right)\right]^{2}(p+2)^{2}}{4 r_{0}^{p+2}}
$$

From Equation (9a),

$$
D_{0, i}=-C_{0, i} \frac{J_{0}\left[z_{i}\left(r_{0}\right)\right]}{Y_{0}\left[z_{i}\left(r_{0}\right)\right]}=C_{0, i} E_{i}
$$

where

$$
E_{i}=-\frac{J_{0}\left[z_{i}\left(r_{0}\right)\right]}{Y_{0}\left[z_{i}\left(r_{0}\right)\right]}
$$

So the gas temperature is

$$
\begin{aligned}
\theta= & \sum_{i=1}^{\infty} C_{0, i}\left(J_{0}\left[z_{i}\left(r^{\prime}\right)\right]+E_{i} Y_{0}\left[z_{i}\left(r^{\prime}\right)\right]\right) e^{-\beta_{i} x^{\prime}} \\
& +\left(C J_{0}\left[\gamma\left(r^{\prime} r_{0}\right)^{\frac{p+2}{2}}\right]+D Y_{0}\left[\gamma\left(r^{\prime} r_{0}\right)^{\frac{p+2}{2}}\right]\right) e^{-500 r_{0} x^{\prime}}
\end{aligned}
$$

Table II Roots of Equation (9)

\begin{tabular}{cccc}
\hline$i$ & $z_{i}\left(r_{0}\right)=\gamma_{i} r_{0}(p=0)$ & $z_{i}\left(r_{0}\right)=\gamma_{i} r_{0}^{3 / 2}(p=1)$ & $z_{i}\left(r_{0}\right)=\gamma_{i} r_{0}^{2}(p=2)$ \\
\hline$z_{j}\left(r_{0}\right) \approx 3.142 \cdot i-1.586$ & $z_{i}\left(r_{0}\right) \approx 1.719 \cdot i-0.8721$ & $z_{i}\left(r_{0}\right) \approx 1.047 \cdot i-0.5338$ \\
2 & 1.360777 & 0.692624 & 0.393456 \\
3 & 4.645900 & 2.523318 & 1.526607 \\
4 & 7.814162 & 4.262888 & 2.590820 \\
5 & 10.96714 & 5.990331 & 3.645581 \\
6 & 14.11506 & 7.713693 & 4.697059 \\
\hline
\end{tabular}




\section{NATURAL CONVECTION AND SOLIDPHASE COMBUSTION}

\section{S. E. WHITNEY, H. J. VILJOEN.}

Chemical Engineering Communications, 190: 393 - 430, 2003 Copyright @ 2003 Taylor \& Francis

with the only remaining unknown being $C_{0, i}$. The third boundary condition gives a method for finding the value of $C_{0, i}$, at $x^{\prime}=0$ :

$$
\begin{aligned}
1= & \sum_{i=1}^{\infty} C_{0, i}\left(J_{0}\left[z_{i}\left(r^{\prime}\right)\right]+E_{i} Y_{0}\left[z_{i}\left(r^{\prime}\right)\right]\right) \\
& +\left(C J_{0}\left[\gamma\left(r^{\prime} r_{0}\right)^{\frac{p+2}{2}}\right]+D Y_{0}\left[\gamma\left(r^{\prime} r_{0}\right)^{\frac{p+2}{2}}\right]\right)
\end{aligned}
$$

From the Sturm-Liouville theorem, two different eigenfunctions are orthogonal if multiplied by the weighting function. In this case, the weighting function is $\left(r^{\prime}\right)^{p+1}$, thus if $i \neq k$

$\int_{r_{0}}^{\infty}\left(J_{0}\left[z_{i}\left(r^{\prime}\right)\right]+E_{i} Y_{0}\left[z_{i}\left(r^{\prime}\right)\right]\right)\left(J_{0}\left[z_{k}\left(r^{\prime}\right)\right]+E_{k} Y_{0}\left[z_{k}\left(r^{\prime}\right)\right]\right)\left(r^{\prime}\right)^{p+1} d r^{\prime}=0$

The coefficients $C_{0, i}$ are then found from the boundary equation above,

$$
C_{0, i}=\frac{\int_{r_{0}}^{\infty}\left(J_{0}\left[z_{i}\left(r^{\prime}\right)\right]+E_{i} Y_{0}\left[z_{i}\left(r^{\prime}\right)\right]\right)\left(1-C J_{0}\left[\gamma\left(r^{\prime} r_{0}\right)^{\frac{p+2}{2}}\right]-D Y_{0}\left[\gamma\left(r^{\prime} r_{0}\right)^{\frac{p+2}{2}}\right]\right)\left(r^{\prime}\right)^{p+1} d r}{\int_{r_{0}}^{\infty}\left(J_{0}\left[z_{i}\left(r^{\prime}\right)\right]+E_{i} Y_{0}\left[z_{i}\left(r^{\prime}\right)\right]\right)^{2}\left(r^{\prime}\right)^{p+1} d r}
$$

These coefficients are large and scatlered when $\beta_{i}<\gamma$ and are small otherwise. The resulting gas temperature is

$0=\sum_{i=1}^{\infty} C_{0, i}\left(J_{0}\left[z_{i}\left(r^{\prime}\right)\right]+E_{i} Y_{0}\left[z_{i}\left(r^{\prime}\right)\right]\right) e^{-\beta_{j} x^{\prime}}+\left(C J_{0}\left[\gamma\left(r^{\prime} r_{0}\right)^{\frac{p+2}{2}}\right]+D Y_{0}\left[\gamma\left(r^{\prime} r_{0}\right)^{\frac{p+2}{2}}\right]\right) e^{-500 r_{0} \cdot x^{t}}$

and the heat transferred between the gas and solid phases at $r^{\prime}=1$ :

$$
\begin{aligned}
q_{g}= & \frac{k(p+2)\left(T_{w}-T_{0}\right)}{2} r_{0}^{\frac{p}{2}} \\
\times & {\left[\begin{array}{c}
\sum_{i=1}^{\infty} \gamma_{i} C_{0, i}\left(J_{1}\left[z_{i}\left(r_{0}\right)\right]+E_{i} Y_{1}\left[z_{i}\left(r_{0}\right)\right]\right) e^{-\beta_{i} x^{t}} \\
+\left(C J_{0}\left[\gamma r_{0}^{\frac{p+2}{2}}\right]+D Y_{0}\left[\gamma r_{0}^{\frac{p+2}{2}}\right]\right) e^{-500 r_{0} \cdot x^{\prime}}
\end{array}\right] }
\end{aligned}
$$




\section{NATURAL CONVECTION AND SOLIDPHASE COMBUSTION}

\section{S. E. WHITNEY, H. J. VILJOEN.}

Chemical Engineering Communications, 190: 393 - 430, 2003 Copyright (C) 2003 Taylor \& Francis

The corresponding Nusselt number at the wall is

$$
\begin{aligned}
\mathrm{Nu}=\frac{(p+2)\left(T_{w}-T_{0}\right)}{2\left(T_{0}+\left(T_{w}-T_{0}\right) e^{-\frac{50 \mathrm{x}}{w}}-T_{r e f}\right)} r_{0}^{\frac{p+2}{2}} \\
\times\left[\begin{array}{c}
\sum_{i=1}^{\infty} \gamma_{i} C_{0, i}\left(J_{1}\left[z_{i}\left(r_{0}\right)\right]+E_{i} Y_{1}\left[z_{i}\left(r_{0}\right)\right]\right) e^{-\beta_{i} x^{t}} \\
+\left(C J_{0}\left[\gamma r_{0}^{\frac{p+2}{2}}\right]+D Y_{0}\left[\gamma r_{0}^{\frac{p+2}{2}}\right]\right) e^{-500 r_{0} x^{t}}
\end{array}\right]
\end{aligned}
$$

Figure 13 shows the Nusselt number comparison from cylindrical solutions and the developing Fluent solutions. The assumed velocity profile, $u=\operatorname{arp}$, does not obey the no-slip condition at $\mathrm{r} 0=1$ which affects the Nusselt number. The Nusselt number is larger negative than predicted by Fluent and the Leveque solution for identical values of a and $p$. The cylindrical solution with plug flow at $u=0: 2 \mathrm{~m} / \mathrm{s}$ gives a result

nearly identical to the Leveque solution with plug flow at $u=0: 5 \mathrm{~m} / \mathrm{s}$. Thus, for the sake of comparison, the gas velocities used in Figure 13 are set such that the velocity at the cylinder wall is $0.2 \mathrm{~m} / \mathrm{s}$ : [ $a=0: 2 \mu \mathrm{s}, \mathrm{p}=0$ ], [ $\mathrm{a}=201 \mathrm{~s}, \mathrm{p}=1$ ], and [a $=20001 \mathrm{~m} \_\mathrm{s}, \mathrm{p}=2$ ].

Importance of Natural Convection Preheating

From Equation [2] the fraction of heat transferred from the reacted solids to the unreacted solids depends on the average heat flux over the remaining cylinder length. These analytical solutions allow a prediction of the importance of including natural convection. Note that these results presented here are for developed flow past the combustion front location [see Figure 4c]. 


\section{NATURAL CONVECTION AND SOLIDPHASE COMBUSTION}

\section{S. E. WHITNEY, H. J. VILJOEN.}

Chemical Engineering Communications, 190: 393 - 430, 2003 Copyright (C) 2003 Taylor \& Francis

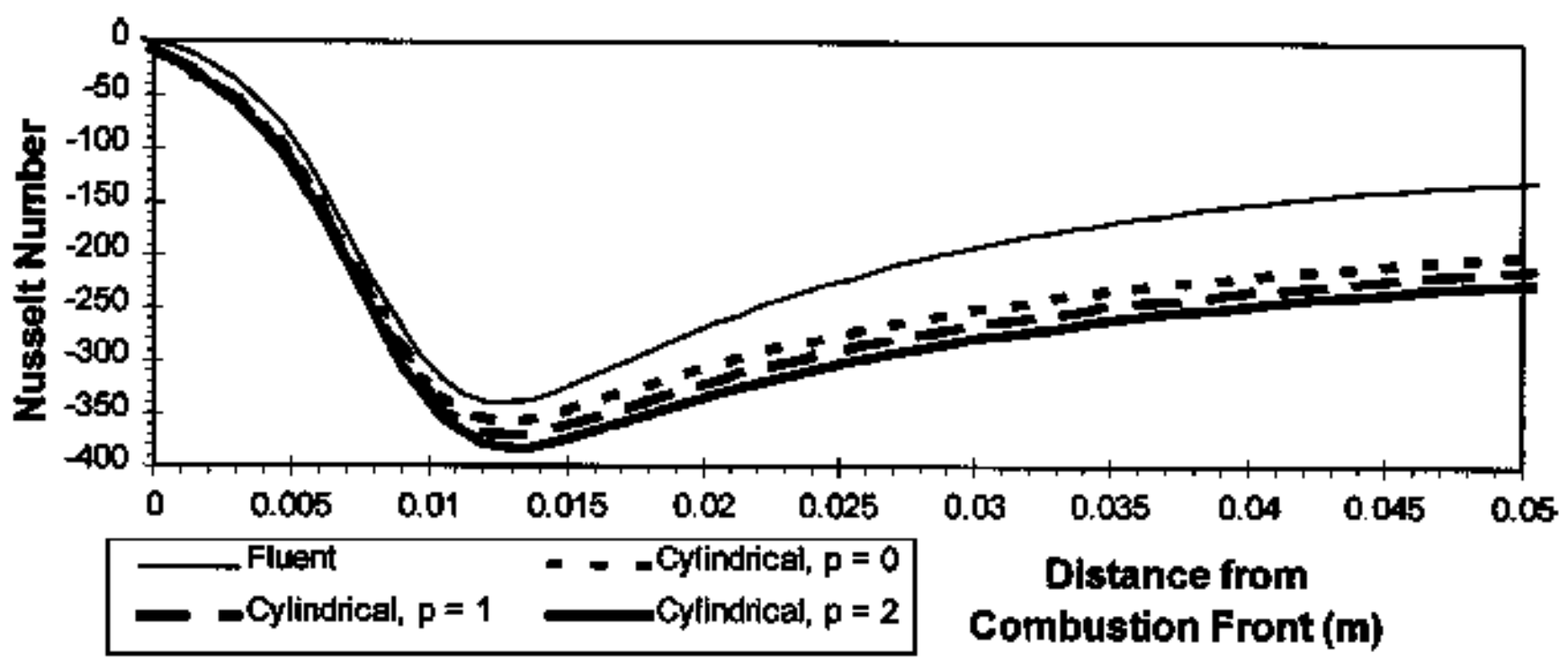

Figure 13. Comparison of fully developed cylindrical solution to Fluent solutions at three different times.

The Leveque solution, Equation [7], gives a simple equation for the ratio of heat transferred by natural convection to the heat transferred by solid conduction. The average heat flux is 
NATURAL CONVECTION AND SOLIDPHASE COMBUSTION

S. E. WHITNEY, H. J. VILJOEN.

Chemical Engineering Communications, 190: 393 - 430, 2003 Copyright @ 2003 Taylor \& Francis

$$
\overline{q_{g}}=\frac{1}{L} \int_{0}^{L} \frac{k\left(T_{0}-T_{w}\right)}{\theta_{\mathrm{int}}}\left(\frac{a}{[p+2]^{2} \kappa x}\right)^{\frac{1}{p+2}} d x
$$

When $p>-1$, this integral is finite with

$$
\overline{q_{g}}=\frac{k\left(T_{0}-T_{w}\right)}{\theta_{\mathrm{int}}}\left(\frac{p+2}{p+1}\right)\left(\frac{a}{[p+2]^{2} \kappa L}\right)^{\frac{1}{p+2}}
$$

Substituting into Equation (2),

$$
\frac{P_{g}}{P_{s}}=\frac{2 L k}{r_{0} \rho_{s} C p_{s} V_{f} \theta_{\text {int }}}\left(\frac{p+2}{p+1}\right)\left(\frac{a}{[p+2]^{2} \kappa L}\right)^{\frac{1}{p+2}}
$$

Since the Leveque solution over predicts the preheating near $x=0$, Equation [13a] should slightly overestimate the effect of natural convection. The cylindrical solution, Equation [12], does not over predict the preheating near $x=0$, but the resulting formula is more complicated. The average heat flux is 
NATURAL CONVECTION AND SOLIDPHASE COMBUSTION

S. E. WHITNEY, H. J. VILJOEN.

Chemical Engineering Communications, 190: 393 - 430, 2003 Copyright (C) 2003 Taylor \& Francis

$\overline{q_{g}}=\frac{1}{L} \int_{0}^{L} \frac{k(p+2)\left(T_{w}-T_{0}\right)}{2} r_{0}^{\frac{p}{2}}\left[\begin{array}{c}\sum_{i=1}^{\infty} \gamma_{i} C_{0, i}\left(J_{1}\left[z_{i}\left(r_{0}\right)\right]+E_{i} Y_{1}\left[z_{i}\left(r_{0}\right)\right]\right) e^{-\beta_{i} x} \\ +\left(C J_{0}\left[\gamma Y_{0}^{\frac{p+2}{2}}\right]+D Y_{0}\left[\gamma F_{0}^{\frac{p+2}{2}}\right]\right) e^{-500 x}\end{array}\right] d x$

$\overline{q_{g}}=\frac{k r_{0}^{\frac{p}{2}}(p+2)\left(T_{w}-T_{0}\right)}{2 L}\left[\begin{array}{l}\sum_{i=1}^{\infty} \frac{\gamma_{i} C_{0, i}}{\beta_{i}}\left(J_{1}\left[z_{i}\left(r_{0}\right)\right]+E_{i} Y_{1}\left[z_{i}\left(r_{0}\right)\right]\right)\left(1-e^{-\beta_{i} L}\right) \\ +\frac{1}{500}\left(C J_{0}\left[\gamma r_{0}^{\frac{p+2}{2}}\right]+D Y_{0}\left[\gamma \gamma_{0}^{\frac{p+2}{2}}\right]\right)\left(1-e^{-500 L}\right)\end{array}\right]$

Substituting into Equation (2),

$$
\frac{P_{g}}{P_{s}}=\frac{-k r_{0}^{\frac{p-2}{2}}(p+2)}{\rho_{s} C p_{s} V_{f}}\left[\begin{array}{l}
\sum_{i=1}^{\infty} \frac{\gamma_{i} C_{0, i}}{\beta_{i}}\left(J_{1}\left[z_{i}\left(r_{0}\right)\right]+E_{i} Y_{1}\left[z_{i}\left(r_{0}\right)\right]\right)\left(1-e^{-\beta_{i} L}\right) \\
+\frac{1}{500}\left(C J_{0}\left[\gamma r_{0}^{\frac{p+2}{2}}\right]+D Y_{0}\left[\gamma r_{0}^{\frac{p+2}{2}}\right]\right)\left(1-e^{-500 L}\right)
\end{array}\right]
$$




\section{NATURAL CONVECTION AND SOLIDPHASE COMBUSTION}

\section{S. E. WHITNEY, H. J. VILJOEN.}

Chemical Engineering Communications, 190: 393 - 430, 2003 Copyright (C) 2003 Taylor \& Francis

\section{CONCLUSIONS}

For combustion antiparallel to gravity, three different outcomes are identified depending on the front velocity.

1. Low combustion front velocities, roughly $1 \mathrm{~cm} / \mathrm{s}$. A starting vortex is formed as the cylinder ignites. This vortex forms a torus around the cylinder that rises against gravity faster than the reaction proceeds. As the torus moves further ahead of the combustion front, steady cylindrical flow of gas forms, rising up along the preform body. The gas preheats the unreacted part of the pre-form.

2. Moderate combustion front velocities, roughly $10 \mathrm{~cm} / \mathrm{s}$. The torus initially rises slightly faster than the combustion front. A preheating zone develops as the torus gains energy from the reaction and deposits this energy on the unburned section of the preform. It is interesting to note that at this combustion front velocity, the torus moves in large oscillations: it gains energy from the reaction and accelerates away from the combustion front; however, it soon loses this energy to the preform, slowing the torus down so that it lags behind the combustion front.

3. High combustion front velocities, $20 \mathrm{~cm} / \mathrm{s}$ or more. The combustion front moves faster than the buoyant torus. Thus the center of the torus is always behind the combustion front leading to high heat flux from the reacted zone to the gas. No preheating is observed. The combustion front induces such high velocities adjacent to the wall that the parallel flow behind the torus becomes unstable and Tollmien-

Schlichting waves develop.

When the combustion front propagates in an oscillating mode, the oscillating velocity has a small but noticeable effect on the heat transfer to and from the gas phase. The magnitude of 


\section{NATURAL CONVECTION AND SOLIDPHASE COMBUSTION}

\section{S. E. WHITNEY, H. J. VILJOEN.}

Chemical Engineering Communications, 190: 393 - 430, 2003 Copyright @ 2003 Taylor \& Francis

this effect depends on the frequency of oscillations. At high frequencies, the inertia of the torus dampens out any effects from the oscillations. All of the results presented here assumed a temperature profile on the solid surface [Figure 1]. From this profilz, the heat transferred to and from the gas was calculated. With this information, a conjugate problem can be solved. That is, the heat transferred will effect the reaction in the solids, which alters the temperature profile. This coupling of Fluent simulations with SHS simulations is currently being studied. An interesting development that comes out of this study is to expand convection preheating beyond natural convection. Natural convection can be enhanced by operating with different gases or at higher pressures. Forced convection could further enhance and stabilize the SHS reactions. If a reaction is slow and significant heat is lost to the atmosphere, forced convection around the cylinder will envelop the cylinder in a gas layer that transports heat from reacted to unreacted zones. 


\title{
NATURAL CONVECTION AND SOLIDPHASE COMBUSTION
}

\author{
S. E. WHITNEY, H. J. VILJOEN.
}

Chemical Engineering Communications, 190: 393 - 430, 2003 Copyright (C) 2003 Taylor \& Francis

\section{NOMENCLATURE}

$A_{c} \quad$ cylinder cross-sectional area

$A_{s} \quad$ cylinder surface area

$C$ particular solution coefficient

$C_{m, i}$ polynomial coefficient

$C_{p} \quad$ gas heat capacity

$C p_{s} \quad$ solid heat capacity

$D \quad$ particular solution coefficient

$D_{0, i} \quad$ polynomial coefficient

$E \quad$ gas internal energy

$E_{\mathrm{i}} \quad$ polynomial coefficient

$f \quad$ frequency of combustion front velocity oscillations

$f(p)$ best fit parameter

$f_{\mathrm{i}} \quad$ solution to the differential equation, Equation (6)

$g$ gravity pointing in the negative axial direction

$h$ heat transfer coefficient

$k$ gas thermal conductivity

$k_{s} \quad$ solid thermal conductivity

$L \quad$ remaining axial cylinder length ahead of the combustion front

$m$ constant in the self-similarity transformation and a counter

$n$ constant in the self-similarity transformation and a counter

Nu Nusselt number

$p \quad$ parameter to adjust gas velocity in analytical solution

$P \quad$ gas pressure

$P_{g} \quad$ power transmitted by gas convection

$P_{0} \quad$ initial gas pressure

$P_{s} \quad$ power transmitted through solid conduction

Pr Prandtl number

$q_{g} \quad$ heat flux normal to the cylinder surface

$q_{s} \quad$ axial heat flux in the solid

$r \quad$ radial distance from the cylinder center axis

$r^{\prime} \quad$ dimensionless radius

$r_{0} \quad$ cylinder radius

$R \quad$ gas constant

$t$ time from ignition

At time step size for CFD calculations

$T$ local gas temperature

$T_{0} \quad$ initial gas temperature and unreacted solid temperature

$T_{r e f}$ reference temperature

$T_{w} \quad$ adiabatic combustion temperature

$T_{w a l l}$ surface wall temperature

$u$ axial gas velocity

$v \quad$ radial gas velocity

$V_{f} \quad$ mean axial combustion front velocity

$V_{c} \quad$ total combustion front velocity

$V_{a} \quad$ amplitude of combustion front velocity oscillations 


\section{NATURAL CONVECTION AND SOLIDPHASE COMBUSTION}

\section{S. E. WHITNEY, H. J. VILJOEN.}

Chemical Engineering Communications, 190: 393 - 430, 2003 Copyright (C 2003 Taylor \& Francis

$x \quad$ axial distance from combustion front

$x^{\prime} \quad$ dimensionless axial position

$\bar{x} \quad$ axial distance from the ignited end

$\bar{x}_{c} \quad$ axial distance of torus from the ignited end with constant combustion front velocity

$\bar{x}_{s} \quad$ axial distance of torus from the ignited end with sinusoidal combustion front velocity

$y \quad$ distance from the solid surface in Leveque solution

$y^{\prime}$ dimensionless distance from solid surface

$z_{\mathbf{i}} \quad$ dimensionless radius

\section{Greek letters}

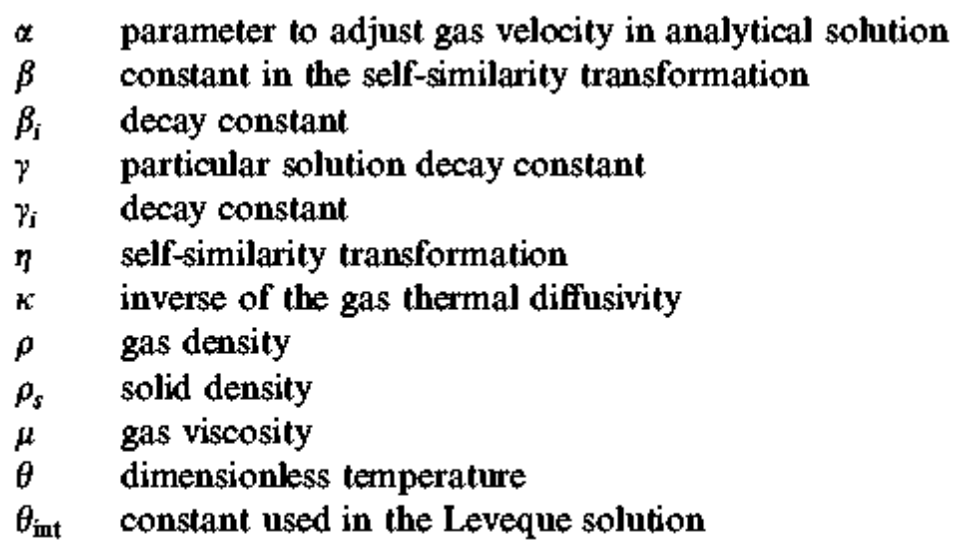

\section{REFERENCES}

Anselmi-Tamburini, U. and Munir, Z. A. [1989]. The propagation of a solid state combustion wave in Ni-Al foils, J. Appl. Phys. 66, 5035. Danen, W. C. and Martin, J. A. [1993]. Energetic composites, U.S. Pat. 5,266,132.

Dyer, T. S. and Munir, Z. A. [1995]. The synthesis of nickel aluminides from multilayer selfpropagating combustion, Metall. Trans. B 26, 587.

Dyer, T. S. et al. [1994]. The combustion synthesis of multilayer Ni-Al systems, Scripta Metall. Mater. 30, 1281.

Gatica, J. E., Viljoen, H. J. and Hlavacek, V. [1989]. Interaction between chemical reaction and natural convection in porous media, Chem. Eng. Sci. 44, 1853.

Ma, E. et al. [1990]. Self-propagating explosive reactions in Ni/Al multilayer thin films, Appl. Phys. Lett. 57, 1262.

Matkowsky, B. J. et al. [1997a]. Upward buoyant filtration combustion, J. Eng. Math. 31, 205.

Matkowsky, B. J. et al. [1997b]. Buoyancy driven filtration combustion, Comb. Sci. Tech. 125, 283. 


\section{NATURAL CONVECTION AND SOLIDPHASE COMBUSTION}

\section{S. E. WHITNEY, H. J. VILJOEN.}

Chemical Engineering Communications, 190: 393 - 430, 2003 Copyright @ 2003 Taylor \& Francis

Sivashinsky, G. [1981]. On spinning propagation of combustion waves, SIAM J. Appl. Math. 40, 432.

Thiart, J. J. et al. [1992]. Stability of non-adiabatic solid-solid-combustion, Comb Sci. Tech. 82, 185.

Vadchenko, S. G. et al. [1987]. Interaction mechanism in laminar bimetal nickeltitianium and nickel-aluminum systems, Comb. Expl. Shock Waves 23, 706.

Van Dyke, M. [1982]. An Album of Fluid Motion, Parabolic Press, Stanford, Calif.

Viljoen, H. J. and Hlavacek, V. [1988]. Chemically driven convection, AIChE J. 33, 1344.

Viljoen, H. J., Gatica, J. E. and Hlavacek, V. [1989]. Convective regimes in fluid media due to the interaction with catalytic surfaces, Phys. Fluids A 1, 274.

Viljoen, H. J., Gatica, J. E. and Hlavacek, V. [1990]. Bifurcation analysis of chemically driven convection, Chem. Eng. Sci. 45, 503.

Weihs, T. P. [1997]. Self-propagating reactions in multilayer materials, In Handbook of Thin Film Processing Technology, IOP Publishing Ltd., Bristol, U.K. 